\title{
CaMKII in Regulation of Cell Death During Myocardial Reperfusion Injury
}

\author{
Yingjie Yang ${ }^{1}$, Kai Jiang ${ }^{2}$, Xu Liu ${ }^{1}$, Mu Qin ${ }^{1 *}$ and Yaozu Xiang ${ }^{2 *}$ \\ ${ }^{1}$ Department of Cardiology, Shanghai Chest Hospital, Shanghai Jiao Tong University, Shanghai, China, ${ }^{2}$ Shanghai East Hospital, \\ School of Life Sciences and Technology, Tongji University, Shanghai, China
}

OPEN ACCESS

Edited by:

Sang-Bing Ong,

The Chinese

University of Hong Kong, China

Reviewed by:

Elena Grossini,

University of Eastern Piedmont, Italy

Hao Zhou,

People's Liberation Army General

Hospital, China

*Correspondence:

Yaozu Xiang

yaozu.xiang@tongji.edu.cn

Mu Qin

qinmu-1001@live.cn

Specialty section:

This article was submitted to

Cellular Biochemistry,

a section of the journal

Frontiers in Molecular Biosciences

Received: 15 February 2021

Accepted: 10 May 2021

Published: 01 June 2021

Citation:

Yang Y, Jiang K, Liu X, Qin M and Xiang Y (2021) CaMKIl in Regulation of

Cell Death During Myocardial

Reperfusion Injury.

Front. Mol. Biosci. 8:668129.

doi: 10.3389/fmolb.2021.668129
Cardiovascular disease is the leading cause of death worldwide. In spite of the mature managements of myocardial infarction (MI), post-Ml reperfusion (I/R) injury results in high morbidity and mortality. Cardiomyocyte $\mathrm{Ca}^{2+}$ overload is a major factor of $\mathrm{I} / \mathrm{R}$ injury, initiating a cascade of events contributing to cardiomyocyte death and myocardial dysfunction. $\mathrm{Ca}^{2+} /$ calmodulin-dependent protein kinase II (CaMKII) plays a critical role in cardiomyocyte death response to $\mathrm{I} / \mathrm{R}$ injury, whose activation is a key feature of myocardial $\mathrm{I} / \mathrm{R}$ in causing intracellular mitochondrial swelling, endoplasmic reticulum (ER) $\mathrm{Ca}^{2+}$ leakage, abnormal myofilament contraction, and other adverse reactions. CaMKII is a multifunctional serine/threonine protein kinase, and CaMKII $\delta$, the dominant subtype in heart, has been widely studied in the activation, location, and related pathways of cardiomyocytes death, which has been considered as a potential targets for pharmacological inhibition. In this review, we summarize a brief overview of CaMKII with various posttranslational modifications and its properties in myocardial I/R injury. We focus on the molecular mechanism of CaMKII involved in regulation of cell death induced by myocardial I/R including necroptosis and pyroptosis of cardiomyocyte. Finally, we highlight that targeting CaMKII modifications and cell death involved pathways may provide new insights to understand the conversion of cardiomyocyte fate in the setting of myocardial I/R injury.

Keywords: CaMKII, posttranslational modification, cardiomyocyte death, I/R injury, cardiovascular disease

\section{INTRODUCTION}

Cardiovascular disease is the leading cause of death worldwide (Heusch, 2020), which accounts for about $30 \%$ of all deaths. Ischemic heart disease accounts for nearly half of all cardiovascular deaths in low- and middle-income countries (Zhou et al., 2016; Prabhakaran et al., 2018; Zhao et al., 2019). During myocardial infarction (MI), the ischemia and hypoxia status due to coronary artery obstruction results in the injury and death of cardiomyocyte. Therefore, timely thrombolytic therapy or percutaneous coronary intervention to restore coronary blood flow is the effective method to reduce acute MI injury and limit MI area (Hausenloy and Yellon, 2008; Hausenloy and Yellon, 2013; Heusch, 2020). However, the reperfusion of MI leads to cardiac injury, such as abnormal cardiac electrical activity, myocardial stunning, microvascular obstruction, and lethal myocardial reperfusion injury (Hausenloy and Yellon, 2013). From the point of view of cell biology, the response of cardiomyocyte during myocardial I/R includes activated immune response, organelle dysfunctions, and shifted metabolic pathways (Hausenloy and Yellon, 2013). The key procedure in reperfusion after MI is the overproduction of ROS by abnormal mitochondrial dynamic in endothelial cell and cardiomyocyte (Wang et al., 2020b) and $\mathrm{Ca}^{2+}$ overload (Talukder et al., 
2009). The mitochondrial homeostasis can be maintained by mitochondrial quality control (MQC) by mitochondrial fission, fusion, or mitophagy (Wang and Zhou, 2020), while during cardiac microvascular I/R, MQC defection leads to ROS overproduction (Wang et al., 2020a), which recruits neutrophils to the lesion (Hausenloy and Yellon, 2013) and triggers the NF- $\mathrm{BB}$ inflammatory pathway (Morgan and Liu, 2011). ROS can also lead to $\mathrm{Ca}^{2+}$ overload by ER stress, which is the main cause of mitochondrial permeability transition pore (mPTP) opening and myofilament hyper-contraction (Hausenloy and Yellon, 2013). The opening of mPTP results in the increased ROS production, which forms a positive feedback between ROS and $\mathrm{Ca}^{2+}$ overload until cell death. CaMKII, as a substrate of $\mathrm{Ca}^{2+}$, is greatly involved in the $\mathrm{ROS}$ and $\mathrm{Ca}^{2+}$ overload feedback. Therefore, it is of great significance to decipher the mechanism of CaMKII involved in regulation of cell death during myocardial I/R injury, contributing to potential drug targets discovery.

$\mathrm{Ca}^{2+} /$ calmodulin (CaM)-dependent protein kinase II (CaMKII) is a multifunctional serine/threonine kinase with four subtypes, including CaMKIIa, CaMKII $\beta$, CaMKII $\gamma$, and CaMKII $\delta$ (Erickson et al., 2011; Gray and Heller Brown, 2014). CaMKIIa and CaMKII $\beta$ are mainly expressed in the nervous system, closely related to memory development (Mayford et al., 1996), while CaMKII $\gamma$ and CaMKII $\delta$ are widely distributed in various organs and tissues (Gray and Heller Brown, 2014). In cardiomyocytes, CaMKII $\delta$ is a dominant subtype (Hund et al., 2010; Erickson et al., 2011; Gray and Heller Brown, 2014). The CaMKII monomer consists of three domains: the N-terminal catalytic domain, the C-terminal binding domain, and the intermediate regulatory domain (Erickson et al., 2011; Gray and Heller Brown, 2014). The variant region (variant domain) locates in the intermediate regulatory domain, whose composition differs according to different CaMKII splicing variants. Taking CaMKII $\delta$ as an example, there are 11 CaMKII $\delta$ variants, among them four variants are located in the heart, including

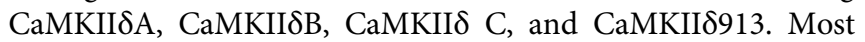

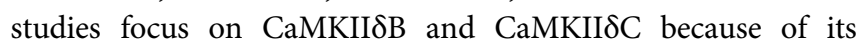
opposite roles in cardiomyocyte. With the nuclear localization sequence (NLS), CaMKII $\delta$ B splicing variant mainly locates in the nucleus, while phosphorylation at specific locus in the NLS may prevent the nuclear transport of CaMKIISB (Srinivasan et al., 1994; Heist et al., 1998; Gray and Heller Brown, 2014). CaMKIISC is in the cytoplasm due to the absence of NLS (Srinivasan et al., 1994). CaMKIIסA locates in the T-tubule, sarcolemmal, and nuclear membrane. As an embryonal CaMKII type, CaMKIISA may strengthen the L-type calcium current for contraction in newborn cardiomyocytes (Beckendorf et al., 2018). It is almost absent in adult cardiomyocytes, but the upregulation of CaMKIISA triggered by MI-induced $\mathrm{HF}$ or chronic HF leads to the hypertrophy or death of cardiomyocyte (Gui et al., 2018). For CaMKII89, its activation also leads to cardiomyocyte injury by inhibiting DNA repair (Zhang M. et al., 2019). Under certain cardiac pathology condition, for example, pression overload or $I / R$ stress, CaMKII $\delta \mathrm{C}$ is activated with the suppression of CaMKII $\delta \mathrm{B}$
(Gray et al., 2017; Ljubojevic-Holzer et al., 2020). However, CaMKIISB is highly expressed in the hypertrophied cardiomyocyte model induced by transverse aortic constriction (TAC), which is degraded by calpain-2 to trigger the mitochondrial apoptosis pathway (Sheng et al., 2015). CaMKIISB is located in the nucleus, but it can also be expressed in the endoplasmic reticulum (ER), membrane, cytosol, and mitochondria (Mishra et al., 2011). Under stress, CaMKII $\delta \mathrm{C}$ is activated by autophosphorylation, and it migrates to the ER and activates two ER receptors: ryanodine receptor 2 (RyR2) and phospholamban (PLN), which were phosphorylated by activated CaMKIISC (Beckendorf et al., 2018) resulting in the $\mathrm{Ca}^{2+}$ leak into cytoplasm. Furthermore, activated CaMKIIסC governs sarcoplasmic reticulum $\mathrm{Ca}^{2+}$-ATPase2 (SerCa2) and stimulates PLN on the nuclear membrane, which enables autophosphorylated CaMKIISC to transfer into the nucleus. Activated CaMKIISC binds and phosphorylates histone deacetylase 4 (HDAC4) protein, causing the disability of nuclear transcription and nuclear location. In addition, CaMKIISC activation also leads to increased intranuclear $\mathrm{Ca}^{2+}$ and aggravates nuclear disorder (Ljubojevic-Holzer et al., 2020). CaMKII $\delta \mathrm{B}$ is also autophosphorylated at the locus Ser332 in its NLS, contributing to its migration to the cytosol (Gray and Heller Brown, 2014). Thus, different subtypes of CaMKII $\delta$ have their own effect on physiological and pathological roles in cardiomyocyte (Figure 1).

A series of studies have shown that myocardial $I / R$ is significantly alleviated by inhibiting the activity of CaMKII either by drug inhibition, including KN93 (Mattiazzi et al., 2007), AIP (Vila-Petroff et al., 2007; Salas et al., 2010), or by gene inhibition (Ling et al., 2013). CaMKII, as a protein kinase, has a series of target proteins in cardiomyocytes. Through posttranslational modification (majority phosphorylation) of these target proteins, CaMKII is involved in the regulation of cardiomyocyte ion homeostasis, contraction, inflammatory response, and programmed cardiomyocyte death. In CaMKII $\delta$ knockout mice in cardiomyocyte, the inflammatory response was suppressed (Willeford et al., 2018), and the apoptosis and cardiac hypertrophy were reduced significantly (Daniels et al., 2015), revealing a protection effect of inhibiting CaMKIIS in cardiomyocyte.

In brief, the majority way to activate CaMKII in cardiomyocyte is by stimulating $\beta 1$-adrenergic receptor $(\beta 1$ AR) (Pereira et al., 2013) and increasing $\mathrm{Ca}^{2+}$ concentration [often by L-type $\mathrm{Ca}^{2+}$ channel (LTCC)] (Beckendorf et al., 2018), but intriguingly, the blockage of $\beta 1$-AR cannot inactive CaMKII (Dewenter et al., 2017). Moreover, its activation is closely related to ER stress in I/R. By phosphorylating RyR2 Ser2814 and PLN Ser16 and Thr17 loci, the SerCA2 was opened, leading to ER stress and $\mathrm{Ca}^{2+}$ leakage (Netticadan et al., 2000). A large amount of $\mathrm{Ca}^{2+}$ entering the cytoplasm directly induced contracture of myofilaments and diastolic dysfunction (Boontje et al., 2011). Furthermore, a large amount of $\mathrm{Ca}^{2+}$ in cytoplasm is transported into mitochondria by mitochondrial $\mathrm{Ca}^{2+}$ unidirectional transporter (MCU), leading to the opening of (mPTP) to cause cardiomyocyte death (Joiner et al., 2012). In addition, mitochondrial stress produces more intracellular ROS and this 


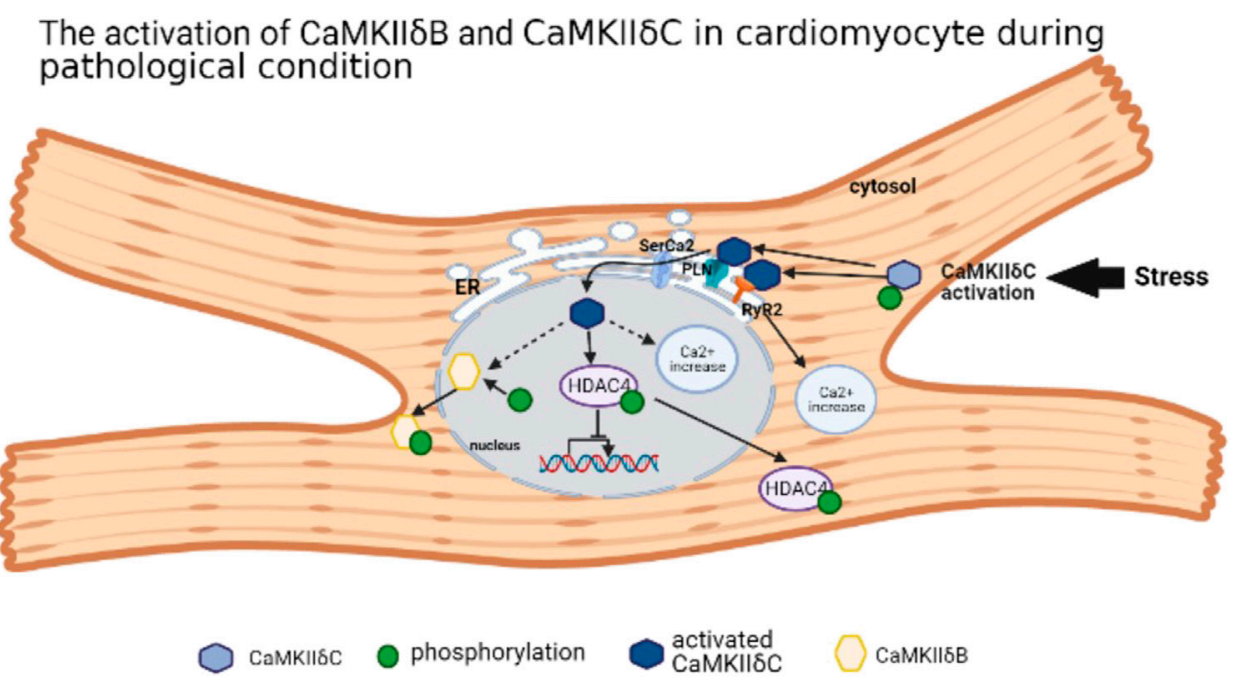

FIGURE 1 | The activation of CaMKIIIB and CaMKIIIC in cardiomyocyte during pathological condition.

stimulates CaMKII and forms a positive feedback, resulting in the accumulation of a large number of intracellular $\mathrm{Ca}^{2+}$ until cell death (Luo et al., 2019). Therefore, from the perspective of organelles, the activation of CaMKII in I/R results in the stress of both ER and mitochondria, the increase of intracellular $\mathrm{Ca}^{2+}$ concentration, and myofilament contracture (Figure 2). Meanwhile, the relative transmembrane ion channels are changed to affect the intracellular ion homeostasis. The detail was not mentioned in this article.

\section{CALMODULIN-DEPENDENT PROTEIN KINASE II MODIFICATION DURING MYOCARDIAL I/R INJURY}

CaMKII's activity is regulated by numerous proteins, with two key steps to activate CaMKII, including the conformational change by $\mathrm{Ca}^{2}{ }^{+} / \mathrm{CaM}$-dependent and posttranslational modification. CaMKII is a dodecamer protein assembly in the intracellular $\mathrm{Ca}^{2+}$ homeostasis, which possesses an autoinhibitory structure. With the elevation of intracellular $\mathrm{Ca}^{2+}$ and tightly combined to the CaM for activation, thus by binding to the regulatory domain, the conformation of dodecamer changes with the N-terminal catalytic domain closing to ATP and substrate protein. Full exposure to the intermediate regulatory domain endows CaMKII prone to oxidation and autophosphorylation (Erickson et al., 2011; Rokita and Anderson, 2012). The catalytic domain transfers ATP's phosphoric group to CaMKII Ser287 locus (subtype $\alpha$ is Ser286) to change it as an active state, and then increases the binding force of phosphorylated-CaMKII to $\mathrm{Ca}^{2+} / \mathrm{CaM}$, which is known as $\mathrm{Ca}^{2+} / \mathrm{CaM}$-dependent direct activation, the most common posttranslational modification of CaMKII (Rokita and Anderson, 2012). Self-phosphorylated CaMKII can be dephosphorylated by protein phosphatases (including PP1 or
PP2A) to restore the self-inhibited state, which are potential targets in cardiac disease like HF, arrhythmia, and MI (Strack et al., 1997; Fischer et al., 2018; El Refaey et al., 2019). While autophosphorylation of Thr305 locus in CaMKII $\gamma$ (Munevar et al., 2008) (Thr305 and Thr306 in CaMKIIa) inhibits the binding ability between CaMKII and $\mathrm{Ca}^{2+} / \mathrm{CaM}$, resulting in decreased CaMKII activity (Cook et al., 2021). Moreover, CaMKII can also be activated by the direct oxidation of CaMKII Met281 and Met282 (a-subtype is CM 280/281) by increased reactive oxygen species (ROS) in cardiomyocytes. This activation manner still requires the initial binding of the $\mathrm{Ca}^{2+} / \mathrm{CaM}$ complex to the CaMKII regulatory domain to release the self-inhibitory structure, and the oxidized component is ROS produced by pathological stimuli or factors such as hyperglycemia, activation of the renin-angiotensin-aldosterone system (RAAS), MI, or heart failure (HF) (Erickson et al., 2008; Luo et al., 2013). As methionine oxidized reductase, methionine sulfone reductase A (MsrA) reverses the oxidative modification of CaMKII, which is a potential drug target to reduce the production of ox-CaMKII (Erickson et al., 2008). Both phosphorylation and oxidation modifications of CaMKII are present in cardiomyocytes under different physiological or pathological conditions. For example, during MI, the expression of CaMKII is significantly increased; meanwhile, aldosterone upregulates its expression through oxidation and phosphorylation, which leads to the deterioration of MI injury (He et al., 2011). Furthermore, by reducing necroptosis key protein RIP3, the activation of CaMKII, both of oxidation and phosphorylation, is suppressed in $\mathrm{I} / \mathrm{R}$ or doxorubicin treatment cardiac injury (Zhang et al., 2016). In 2013, oxygen-linked acetylglucosamine transferase (OGT) glycosylation CaMKII Ser280 (a-subtype Ser279) and the formation of $\beta$-N-acetylglucosamine modification at $\mathrm{O}$-site were demonstrated. This modification of CaMKII occurs in response to high-glucose stimulation (Erickson et al., 2013), while oxygen-linked acetylglucosaminase (OGA) sponges the 


\section{CaMKIII protein structure (Human)}

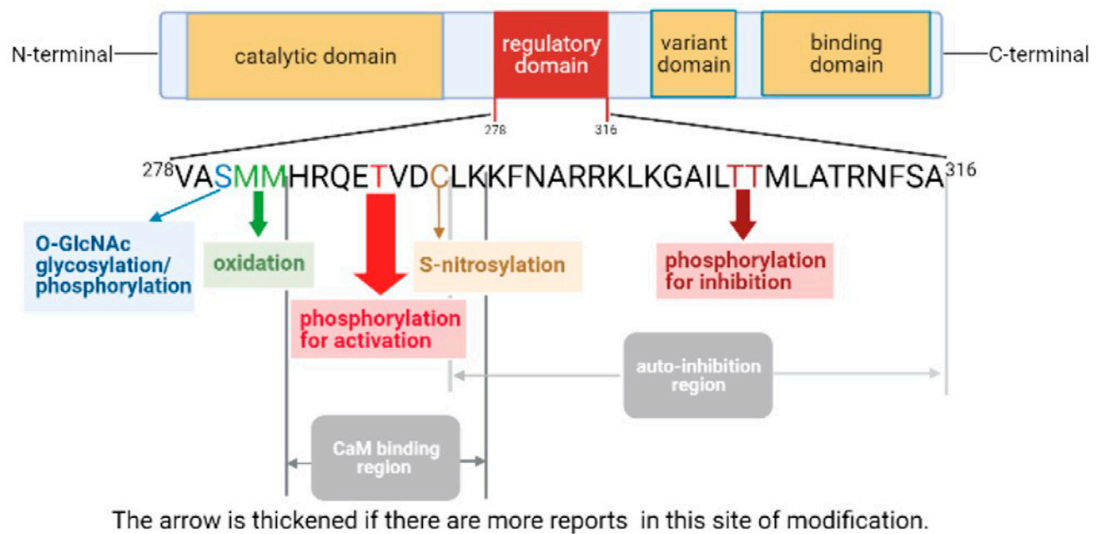

FIGURE 2 | The effect of CaMKII $\delta$ related pathway in cardiomyocyte during I/R.

glycosylation at the Ser280 of CaMKII, thus reversing the glycosylation modification of CaMKII (Zou et al., 2012). In addition, CaMKII can also be activated by nitrosylation in cardiomyocyte. Among them, $\beta$-adrenergic receptors ( $\beta$-AR) induce the nitric oxide (NO) intracellular production, which activates CaMKII by nitrosylation rather than nitrosylating other targets like RyR2, leading to $\mathrm{ER} \mathrm{Ca}^{2+}$ leak and the occurrence of arrhythmias (Gutierrez et al., 2013). Through binding to $\mathrm{Ca}^{2+} / \mathrm{CaM}$, NO simultaneously nitrosylates the Cys289 residue in CaMKIIa, which reduces autophosphorylation of Thr286 (Coultrap and Bayer, 2014). In the cardiomyocyte, the S-nitrosylation of Cys290 activates CaMKIIS, contributing to downstream $\mathrm{Ca}^{2+}$ leak. However, it can be reversed by S-nitrosylation of Cys273 (Erickson et al., 2015). Thus, various CaMKII $\delta$ modifications are essential in cardiac I/R injury (See Figure 3; Table 1).

\section{CaMKIII Thr287 Phosphorylation}

Phosphorylation of CaMKII $\delta$ Thr287 occurs in many physiological conditions, and almost all cardiac pathological conditions require the activation of CaMKII $\delta$ by phosphorylation. During MI, the upregulation of CaMKII phosphorylation affected the expression and the phosphorylation of ER receptors including RyR2, PLN, and SerCa2, which leads to ER dysfunction in post-MI HF (Netticadan et al., 2000). During reperfusion, CaMKII is autophosphorylated and redistributes into the cytoplasm (Uemura et al., 2002). Through the computer mathematical model and biochemical imaging technology applying to the MI model, it was confirmed that the autophosphorylation of CaMKII in the border zone of infarction was increased, which resulted in abnormal intracellular $\mathrm{Ca}^{2+}$ homeostatic and influences on sodium channels to reduce upstroke velocity of action potential (Hund et al., 2008). In an abnormal cardiac contractility after $\mathrm{MI}$, increased intracellular $\mathrm{Ca}^{2+}$ leads to the enhanced myofilament contraction ability (Zhang Y. et al., 2019).
CaMKIISC's phosphorylation plays an important role in the filament reactivity by modulating the phosphorylation of myofilament associated protein, myosin-binding protein $\mathrm{C}$ (Boontje et al., 2011; Reil et al., 2020). In addition, CaMKIISC phosphorylation can activate NF- $\mathrm{BB}$-related pathways to enhance TNF- $\alpha$ expression in response to $I / R$ injury (Gray et al., 2017). During MI, CaMKII phosphorylation leads to the phosphorylation of Nav1.5, a cardiac sodium channel (Howard et al., 2018), and the reverse of Ito (a cardiac potassium channel) by decreasing Kv4.3 gene (Tao et al., 2020; Tinaquero et al., 2020), inducing arrhythmias. In the case of $\mathrm{I} / \mathrm{R}$ injury, CaMKII phosphorylation can also be regulated by zinc transporters or (Wang et al., 2020c) brain-derived neurotrophic factor (BDNF) (Lee et al., 2018). Thus, CaMKII phosphorylation plays a role in ER stress, intracellular ion stabilization, and contractility in cardiomyocytes.

\section{CaMKII $\delta$ Met281/282 Oxidative Modification}

Since 2008, ROS was found to directly oxidize CaMKII in Met281 and Met282 sites and to induce its activation (Erickson et al., 2008). Ox-CaMKII was identified to be associated with various diseases including cardiovascular disease, arrhythmia, cancer, and asthma (Anderson, 2015). Ox-CaMKII function firstly observed in cardiac disease is the induction the apoptosis of sinoatrial node (SAN) cells, contributing to sinus node dysfunction (SND). By inhibiting the NADPH oxidase in the angiotensin II (Ang II) infusion mice model, ox-CaMKII is suppressed, thus improving the survival of SAN cells, suggesting that ox-CaMKII may be the cause of SND by triggering SAN cell death (Swaminathan et al., 2011). In terms of $\mathrm{MI}$, activation of the TLR/MyD88/NF- $\kappa \mathrm{B}$ pathway after MI induces CaMKII oxidation, leading to myocardial cell death. Knocking out MyD88, ox-CaMKII production was inhibited to protect the adverse hypertrophy and inflammation by LPS and MI (Singh et al., 2012). In addition, increased ox-CaMKII in mitochondria contributes to sudden death in diabetic MI, while 


\section{The effect of CaMKII related pathway in cardiomyocyte during $\mathrm{I} / \mathrm{R}$}

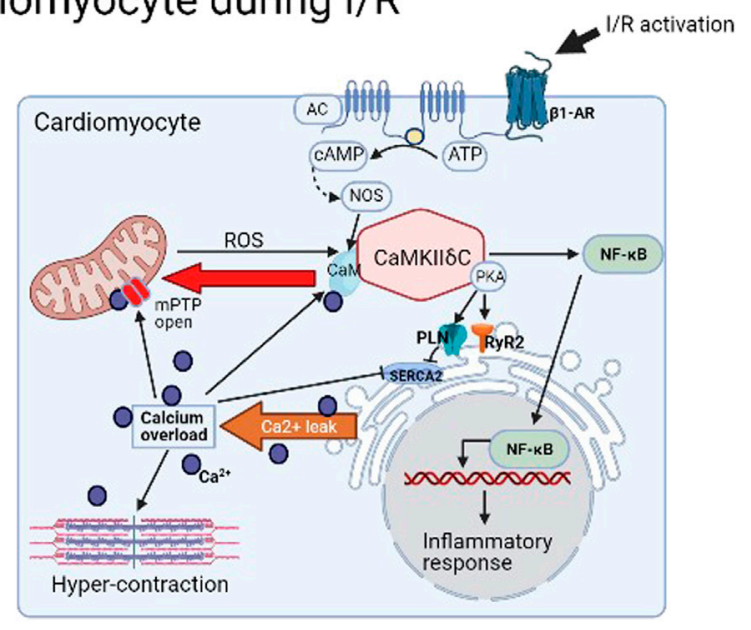

FIGURE 3 | Schema of human CaMKIII protein structure.

mitochondrial antioxidants inhibited ox-CaMKII and increased the number of cardiomyocyte survival (Luo et al., 2013). OxCaMKII also exerts an important role in the development and maintenance of atrial fibrillation (Yoo et al., 2018), (Yang et al., 2020). Recent studies showed that ROS and O-GlcNAcylation protein (OGN) are elevated in diabetic heart disease, both of which induce atrial fibrillation. However, only ROS-induced CaMKII oxidation, while OGN is dependent on CaMKIIinduced atrial fibrillation not by CaMKII glycosylation (Mesubi et al., 2021). Therefore, the interaction between the oxidation and other posttranslational modifications of CaMKII in myocardial I/R injury remains to be elucidated. In fact, several inhibitors, such as protein phosphatase 1 inhibitor 1 (I1PP1) and Chinese patent medicines, also alleviate diabetes and I/R-related myocardial injury by inhibiting ox-CaMKII (Luo et al., 2019; Liu et al., 2020).

\section{CaMKIII Cys290 Nitrosylation Modification}

Before the discovery of the nitrosylation modification of CaMKII, studies have demonstrated that $\mathrm{NO}$ and CaMKII exhibited interaction, but the site and the role have not been clarified for a long time. In ventricular arrhythmias, phosphorylation of RyR2 receptor occurs under the condition of intracellular nitroso-redox imbalance; further study showed that its phosphorylation is related to CaMKII activation (Cutler et al., 2012). An upstream event could be represented by the stimulation of $\beta$-receptor stimulation, which activates CaMKII to induce $\mathrm{ER} \mathrm{Ca}^{2+}$ leakage, but the specific mechanism and pathway remain to be elucidated (Curran et al., 2014). Until 2014, the CaMKIIa S-nitrosylation was first identified (Coultrap and Bayer, 2014), and further studies illustrated that the Cys290 nitrosylation of CaMKII by NO autonomously activates CaMKII (Erickson et al., 2015). Its activation also induces phosphorylation and nitrosylation of downstream RyR2 receptors, which can be abolished by Cys273 mutation, suggesting the potential pathogenicity and inhibitory site of CaMKII protein-causing cardiomyocyte death (Erickson et al., 2015).

\section{CaMKII $\delta$ Ser280 Glycosylation Modification}

$\mathrm{O}-\mathrm{N}$-acetylglucosamine (O-GlcNAc) glycosylation of CaMKII mediated by O-GlcNAc transferase (OGT) is a unique form of activation that does not affect $\mathrm{Ca}^{2+} / \mathrm{CaM}$-induced direct activation of CaMKII. Similar to other phosphorylation, $\mathrm{O}-\mathrm{GlcNAc}$ glycosylation of CaMKII is an inducible, reversible, and dynamic posttranslational modification. In addition to OGT, another glycosidase O-GlcNAcase (OGA) also regulates the activity of CaMKII. Unlike phosphorylation mediated by huge amounts of kinases and phosphatases, the reversible modification of O-GlcNAc glycosylation is only catalyzed by glycosylation (OGT) and deglycosylation (OGA) (Erickson et al., 2013).

$\mathrm{O}-\mathrm{GlcNAc}$ is closely related to the level of glucose, so CaMKII glycosylation is often modulated by the level of glycemia in physiology or pathology status. Glucose deprivation has been reported significantly to increase O-GlcNAc levels, and it is associated with decreased OGA but not with increased OGT (Zou et al., 2012). In neonatal cardiomyocytes, glucose deprivation and heat shock both increase O-GlcNAc levels, which is overturned by CaMKII inhibitor KN93, suggesting that intracellular CaMKII activation induced by $\mathrm{Ca}^{2+}$ plays a key role in regulating the increase in O-GlcNAc levels (Zou et al., 2012). CaMKII is highly expressed and highly active in the hearts of patients with diabetes and HF, especially CaMKII O-GlcNAc glycosylation. The first research about OGT published in 2010 showed that OGT deletion worsens the cardiac function in post-MI HF (Watson et al., 2010). In terms of hyperglycemia, the sudden elevation of glycemia results in the induction of arrhythmias due to CaMKII activation through glycosylation (Erickson et al., 2013). Further studies showed a transient increase in glycemia 
TABLE 1 | Overview of CaMKII posttranslational modification (CaMKIII as an example).

\begin{tabular}{llll}
\hline $\begin{array}{l}\text { CaMKII posttranslational } \\
\text { modification }\end{array}$ & \multicolumn{1}{c}{ Modification locus } & \multicolumn{1}{c}{ Substrate/donor } \\
\hline Phosphorylation & Thr287 & $\begin{array}{l}\text { Substrate: protein calmodulin and donor: ATP } \\
\text { autophosphorylation } \\
\text { ATP autophosphorylation }\end{array}$ & Activation \\
Phosphorylation & $\begin{array}{l}\text { Thr306 and Thr307 maybe (no report in } \\
\text { CaMKII) }\end{array}$ & ROS \\
Oxidation & Met281 and Met282 & NO \\
S-nitrosylation & Cys290 & NO & Activation \\
S-nitrosylation & Cys273 & OGT & Activation \\
O-GlcNAc glycosylation & Ser280 & Inhibition \\
\hline
\end{tabular}

due to stress may increase the speed of $\mathrm{Ca}^{2+}$ waves and downregulate the cardiac potassium channel amplitude through CaMKIIS-Ser280-GlcNAcylation. Moreover, chronic hyperglycemia and CaMKII activation during diabetes downregulate $\mathrm{K}^{+}$channel expression and function, both of which increase sensitivity to arrhythmias possibly by O-GlcNAc glycosylation (Hegyi et al., 2020; Miura et al., 2020). However, when acute hyperglycemia was used to induce the glycosylation of CaMKII in animal experiments, only a low arrhythmic substrate was observed and atrial fibrillation was not induced (Manninger et al., 2020). Moreover, the most recent study showed that the locus of Ser280 in CaMKIIS acts as phosphorylation rather than glycosylation in the model of AF (Mesubi et al., 2021), which should be further verified and explored in its change of conformation and function. In terms of MI or myocardial $\mathrm{I} / \mathrm{R}$, the glycosylation of CaMKII was increased in the type 2 diabetes mellitus (Wang et al., 2018). CaMKII glycosylation induces the occurrence of myocardial cell damage and a series of in vivo and in vitro experiments proved, suggesting O-GlcNAc influences myocardial I/R injury through various ways (Ngoh et al., 2010; Dassanayaka and Jones, 2014). Its various functions in the nervous system are also new fields not only in heart diseases but also in neuronal functions (Lagerlöf et al., 2016).

\section{CALMODULIN-DEPENDENT PROTEIN KINASE II INVOLVED IN INFLAMMATORY RESPONSE AND VARIOUS CARDIOMYOCYTE CELL DEATH MODES \\ Calmodulin-Dependent Protein Kinase II and Apoptosis}

As early as 1996, it was found that apoptosis was the main death mode of cardiomyocyte after MI, which accounts for more than $90 \%$ of death myocyte $2 \mathrm{~h}$ after $\mathrm{MI}$, and the necrosis of myocardial cells reached the peak after apoptosis (Kajstura et al0., 1996). The cell death modes of cardiomyocytes during $\mathrm{I} / \mathrm{R}$ injury are various, and the cause of cell death owning to CaMKII may be dependent on the accumulation of intracellular $\mathrm{Ca}^{2+}$. In apoptosis, $\mathrm{Ca}^{2+}$ accumulation is relatively slow in apoptosis and other forms of programmed cell death (mainly necroptosis) (Wang et al., 2010). In 2006, by modulating myocardial CaMKII through the expression of highly specific CaMKII inhibitory peptide AC3-I, researchers showed that AC3I mice had reduced $\mathrm{ER} \mathrm{Ca}^{2+}$ content and were resistant to apoptosis induced by isoproterenol (ISO) and MI, suggesting that inhibition of CaMKII or ER $\mathrm{Ca}^{2+}$ leakage prevents cardiomyocyte apoptosis in pathological condition (Yang et al., 2006). CaMKII inhibition reduced caspase- 3 activation and the number of TUNEL-positive cells and increased the Bcl-2/Bax ratio (VilaPetroff et al., 2007). As the upstream of CaMKII, $\beta 1-A R$, as a common target in I/R injury or LPS stimulation, induces both apoptosis and necrosis of cardiomyocytes (Yoo et al., 2009; Wang et al., 2015). PLN and RyR2, two major activated CaMKII downstream substrates on ER, mediate apoptosis in myocytes. In PLN double-mutants mice and constitutive RyR2 activation mice (RyR2 S2814D mice), the infarct size increased and myocardial apoptosis happened after I/R damage (Di Carlo et al., 2014). Moreover, apoptosis was reduced in CaMKII $\delta$ knockout mouse in the TAC model, maybe due to Akt inactivation (Toischer et al., 2010). For drugs inhibition, estrogen inhibits CaMKII expression by protein kinase A (PKA), thereby alleviating ISO-induced cardiac I/R injury (Ma et al., 2009).

\section{Calmodulin-Dependent Protein Kinase II and Necrosis}

The previous study has demonstrated that the necrosis of myocytes, which is often accompanied by other cell death mode (for example apoptosis), is one of the reasons for the progressive loss of myocardial cells after MI despite its small proportion in cardiomyocyte's death after MI (Kajstura et al., 1996). When the accumulation rate of $\mathrm{Ca}^{2+}$ is relatively fast in cardiomyocyte $\left(\mathrm{Ca}^{2+}\right.$ overload occurs rapidly), ER uptakes and releases more $\mathrm{Ca}^{2+}$, resulting to the hyper-contraction of myofilament and mitochondrial hyperpermeability (GarciaDorado et al., 2012), thus leads to mPTP and MCU opening and loss of mitochondrial membrane potential (mitoptosis) (Joiner et al., 2012). With the dysfunction of mitochondria, ATP cannot be produced and necrosis happens (Zhu et al., 2021). Thus few studies have been conducted on myocardial necrosis due to the relatively moderate intracellular $\mathrm{Ca}^{2+}$ accumulation during $\mathrm{I} / \mathrm{R}$ injury. From the perspective of molecular biology, CaMKII inhibition reduces LDH release, suggesting that CaMKII inhibition could prevent necrosis 


\section{CaMKII induced cardiomyocyte-related death forms and its pathways}

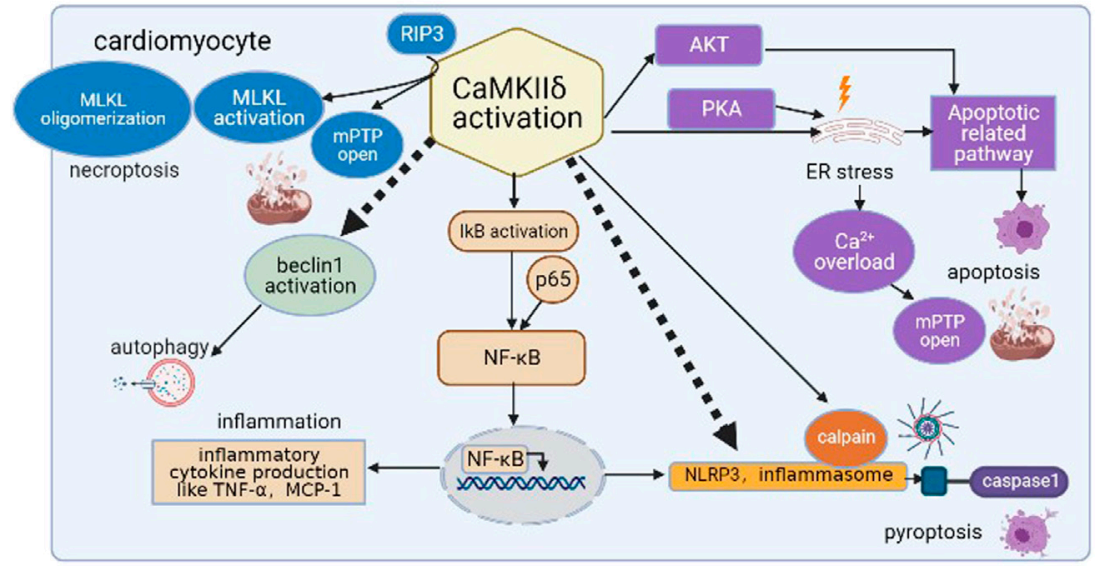

FIGURE 4 | CaMKIl induced cardiomyocyte-related death forms and its pathways.

process (Vila-Petroff et al., 2007). As the upstream of CaMKII, the activation of $\beta 1-\mathrm{AR}$ induces both apoptosis and necrosis of cardiomyocytes during I/R (Yoo et al., 2009). Furthermore, phosphorylation of PLN and RyR2, two major activated CaMKII downstream substrates on ER, mediates necrosis of cardiomyocytes. Constitutive activation of RyR2 phosphorylation site S2814 gives rise to the increase of infarct size after I/R, myocardial necrosis happened, while the lack of PLN activation can also aggravate myocardial I/R injury, suggesting that CaMKII mediates necrosis of myocardial cells through phosphorylation on RyR2 (Di Carlo et al., 2014). For PLN, its activation involves the reverse of $\mathrm{ER} \mathrm{Na}^{+}-\mathrm{Ca}^{2+}$ exchanger (NCX) pattern, then induces a cascade to mitochondrial effector like MCU or MPTP to induce mitoptosis, ${ }^{27}{ }^{35}$ a cell death mode was often classified into necrosis. Until now, more pathways and chemical substrates are related to CaMKII and mitoptosis in myocardial $\mathrm{I} / \mathrm{R}$ (Wang J. et al., 2021). As the development of biotechnology, a new mode of programmed cell death, necroptosis, has been reported (Zhou et al., 2016).

\section{Calmodulin-Dependent Protein Kinase II and Pyroptosis/Inflammatory-Related Cell Death}

Pyroptosis has been widely reported in cell and organ injury, and its mechanism has been gradually clarified in recent 5 years. In brief, pyroptosis is an under-controlled programmed inflammatory death mediated by caspase- $1,-4,-5$, and its effectors gasdermin family (Shi et al., 2017). The classical pathway of pyroptosis is the activation of inflammasome; the most common is NLRP3 inflammasome (He et al., 2016). There are more research studies focused on MI and pyroptosis; however, there is still no relevant report linking CaMKII and cardiomyocyte pyroptosis (cell perforation by gasdermin family) except several research studies focused on the activation of NLRP3 inflammasome by CaMKII. Inflammasomes were activated prior to Ang II-induced cardiomyocyte death in the normal mice group and weakened in CaMKII $\delta$ knockout mice, and inflammasomes can recruit immune cells like macrophage to infiltrate myocardium, causing the cardiac remodeling (Willeford et al., 2018). Pression overload acts as the induction of NLRP3 inflammasome, which is accompanied by the expression of inflammatory genes (Suetomi et al., 2018; Suetomi et al., 2019). Moreover, the blockage of calpain (CAPN) could inhibit the NLRP3/ASC/caspase-1 pyroptosis pathway in the hypoxia-reoxygenation process of cardiomyocytes (Yue et al., 2019), while CAPN is closely related to CaMKII. In I/R, calpain binds to phosphorylated CaMKII and promotes the transport of phosphorated CaMKII and CapN1 to the ER membrane, thus activating the downstream receptor RyR2 ( $\mathrm{Lu}$ et al., 2020). Despite this programmed inflammatory cell death mode, pyroptosis, CaMKII also mediates $\mathrm{I} / \mathrm{R}$ injury through activation of the NF- $\mathrm{B}$ inflammatory pathway. CaMKII $\delta$ depletion attenuates $\mathrm{I} / \mathrm{R}$-induced inflammation and upregulated nuclear factor- $\kappa \mathrm{B} \quad(\mathrm{NF}-\kappa \mathrm{B})$; meanwhile, its activation is independent of cardiomyocyte necrosis. The expression of activated CaMKII in cardiomyocytes contributes to phosphorylation of I $\mathrm{KB}$ kinase $(\mathrm{I} \kappa \mathrm{K})$ and the increase of nuclear factor p65, suggesting that CaMKII may activate NF- $\kappa$ B through I $\kappa \mathrm{K}$ during I/R (Ling et al., 2013). Further studies showed that selective activation of CaMKII $\delta \mathrm{C}$ during I/R was more likely to activate NF$\kappa \mathrm{B}$ and expressed more TNF- $\alpha$ compared with activation of CaMKIISB, suggesting the acute activation of CaMKIISC and NF- $\mathrm{B}$ in reperfusion pathogenesis (Gray et al., 2017). In addition, myocardial knockdown of CaMKII $\delta$ significantly reduces the activation of NF- $\mathrm{kB}$, the expression of inflammatory chemokines and cytokines in Ang II infusion, while with the infusion of Ang II, CaMKII-dependent inflammatory gene expression and inflammasome development could be detected before the recruitment of macrophage, ultimately brings about cardiac fibrosis (Willeford et al., 2018). CaMKIIסC can also induce 
TABLE 2 | Related drugs targeting CaMKII in disease.

\begin{tabular}{|c|c|c|c|c|}
\hline CaMKII inhibitor & Subject & $\begin{array}{l}\text { Clinical } \\
\text { trial }\end{array}$ & Disease treatment & Reference \\
\hline $\mathrm{KN}-93$ & Rabbit and rat & No & Hypokalemia-induced ventricular arrhythmia & Pezhouman et al. (2015) \\
\hline $\mathrm{KN}-62$ & Rat & No & Heart I/R injury & Lu et al. (2020) \\
\hline AIP & Rat & No & Diabetes heart disease & Daniels et al. (2018) \\
\hline Rimacalib (SMP-114) & Human & Yes & $\begin{array}{l}\text { Rheumatoid arthritis (RA); phase 2, NCT00296257; and ventricular } \\
\text { arrhythmia }\end{array}$ & $\begin{array}{l}\text { Neef et al. (2017); Westra et al. } \\
\text { (2009) }\end{array}$ \\
\hline RA608 & $\begin{array}{l}\text { Human and } \\
\text { mouse }\end{array}$ & No & Arrhythmia and HF & Mustroph et al. (2020) \\
\hline Ranolazine & $\begin{array}{l}\text { Human and } \\
\text { canis }\end{array}$ & Yes & $\begin{array}{l}\text { Ventricular arrhythmia and related death, chronic kidney disease-induced } \\
\text { arrhythmia, MI, and phase 2, NCT02360397 }\end{array}$ & $\begin{array}{l}\text { Zareba et al. (2018); Ke et al. (2020); } \\
\text { Le et al. (2020) }\end{array}$ \\
\hline PaAIP2 & Mouse and rat & No & Neuronal dysplasticity & Murakoshi et al. (2017) \\
\hline $\begin{array}{l}\text { CN21(LY900014)/ } \\
\text { tatCN21 }\end{array}$ & Human & Yes & Type 2 diabetes mellitus and Phase 3, NCT04605991 & Tao-Cheng et al. (2013) \\
\hline RA306 & $\begin{array}{l}\text { Rat and } \\
\text { mouse }\end{array}$ & No & $\mathrm{HF}$ & Beauverger et al. (2020) \\
\hline
\end{tabular}

TABLE 3 | Drugs or inhibitors affecting CaMKIl-related pathways in I/R.

\begin{tabular}{|c|c|c|c|c|c|c|}
\hline Drug/inhibitor & $\begin{array}{l}\text { Subject and I/R } \\
\text { method }\end{array}$ & Function & $\begin{array}{l}\text { Related molecular } \\
\text { and pathway }\end{array}$ & $\begin{array}{l}\text { The inhibition of } \\
\text { death pathway }\end{array}$ & $\begin{array}{l}\text { Result after } \\
\text { medication }\end{array}$ & Reference \\
\hline \multirow[t]{2}{*}{ Melatonin } & $\begin{array}{l}\text { 1. SD rat, ex vivo I/ } \\
\mathrm{R} \text {, and chronic } \\
\text { intermittent hypoxia }\end{array}$ & $\begin{array}{l}\text { 1. Maintain } \mathrm{ER} \mathrm{Ca}^{2+} \text { homeostasis } \\
\text { and enhance antioxidant enzyme } \\
\text { activity }\end{array}$ & 1. Unknown & $\begin{array}{l}\text { 1. Inflammatory } \\
\text { response }\end{array}$ & $\begin{array}{l}\text { 1. Inflammation and } \\
\text { fibrosis improved }\end{array}$ & $\begin{array}{l}\text { Yeung et al. } \\
\text { (2015); Zhou } \\
\text { et al. (2018) }\end{array}$ \\
\hline & 2. Mouse in vivo $\mathrm{I} / \mathrm{R}$ & $\begin{array}{l}\text { 2. Attenuation I/R-triggered } \\
\text { microvascular necroptosis }\end{array}$ & $\begin{array}{l}\text { 2. RIPK3-PGAM5- } \\
\text { CypD-mPTP } \\
\text { pathway }\end{array}$ & 2. Necroptosis & $\begin{array}{l}\text { 2. Reduce endothelial } \\
\text { necroptosis }\end{array}$ & \\
\hline SGLT2 inhibitor & $\begin{array}{l}\text { Rat and mouse with } \\
\text { many studies }\end{array}$ & $\begin{array}{l}\text { Maintaining intracellular ion } \\
\text { homeostasis, inhibiting reactive } \\
\text { oxygen species, and AMPKa } \\
\text { activation }\end{array}$ & $\begin{array}{l}\text { Unknown, maybe } \\
\text { AMPK activation }\end{array}$ & $\begin{array}{l}\text { Inflammatory } \\
\text { response, stress, } \\
\text { and oxidation }\end{array}$ & $\begin{array}{l}\text { I/R Ml area maintained in } \\
\text { the short term but } \\
\text { decreased in the long } \\
\text { term }\end{array}$ & $\begin{array}{l}\text { Andreadou et al } \\
\text { (2020) }\end{array}$ \\
\hline $\begin{array}{l}\text { 3, 4-dihydroxy } \\
\text { flavonol }\end{array}$ & Rat in vivo $1 / \mathrm{R}$ & $\begin{array}{l}\text { Enhance the respiratory function } \\
\text { and decrease the ROS production }\end{array}$ & Inhibit mPTP open & Mitoptosis & $\begin{array}{l}\text { Preservation of } \\
\text { mitochondrial function }\end{array}$ & $\begin{array}{l}\text { Woodman et al. } \\
\text { (2014) }\end{array}$ \\
\hline Melatonin & Mouse in vivo I/R & Inhibition of RIP3 maybe & $\begin{array}{l}\text { RIP3-MLKL/CaMKII } \\
\text { pathway }\end{array}$ & $\begin{array}{l}\text { Necroptosis and } \\
\text { inflammatory } \\
\text { response }\end{array}$ & $\begin{array}{l}\text { Myocardial necrosis and } \\
\text { ROS production were } \\
\text { improved }\end{array}$ & $\begin{array}{l}\text { Yang et al. } \\
(2018)\end{array}$ \\
\hline ZYZ-803 & Mouse in vivo $1 / R$ & $\begin{array}{l}\text { Hydrogen sulfide and nitric oxide } \\
\text { are produced to maintain } \\
\text { intracellular endoplasmic } \\
\text { reticulum stability and influence } \\
\text { necroptosis pathways }\end{array}$ & $\begin{array}{l}\text { RIP3/CaMKII } \\
\text { pathway }\end{array}$ & $\begin{array}{l}\text { Necroptosis and } \\
\text { ER stress }\end{array}$ & $\begin{array}{l}\text { Reduce infarct size and } \\
\text { improve cardiac function }\end{array}$ & $\begin{array}{l}\text { Chang et al. } \\
(2019)\end{array}$ \\
\hline $\begin{array}{l}\text { Total saponins of } \\
\text { Panax } \\
\text { notoginseng }\end{array}$ & Mouse in vivo $\mathrm{I} / \mathrm{R}$ & $\begin{array}{l}\text { Enhancing glucose deprivation } \\
\text { induces autophagy, antiplatelet } \\
\text { aggregation, angiogenesis, and } \\
\text { endothelial migration }\end{array}$ & $\begin{array}{l}\text { AMPK and CaMKII } \\
\text { phosphorylation }\end{array}$ & $\begin{array}{l}\text { Induction of } \\
\text { autophagy }\end{array}$ & $\begin{array}{l}\text { Enhance endothelial cell } \\
\text { migration and } \\
\text { angiogenesis }\end{array}$ & $\begin{array}{l}\text { Wang D. et al., } \\
(2021)\end{array}$ \\
\hline
\end{tabular}

cardiomyocyte to express pro-inflammatory chemokine signal like macrophage inflammatory protein 1 (MIP-1) in post-MI through the inflammatory pathway rather than induction of cell death in post-MI early state and mediate changes in immune cells infiltration and cardiac remodeling, suggesting that CaMKII modulates post-pathological infarction (Weinreuter et al., 2014). The expression of inflammatory genes can also be triggered by activated CaMKII in cardiomyocytes in the mice TAC model, while by knocking out CaMKII $\delta$, inhibiting monocyte chemotactic protein-1 (MCP-1), and suppressing inflammasome are able to effectively reverse cardiac remodeling (Suetomi et al., 2018; Suetomi et al., 2019). Moreover, a critical protein in the inflammatory pathway, MyD88, also triggers cardiac hypertrophy and cardiomyocyte death in MI through oxidation of CaMKII (Singh et al., 2012). To inactivate NLRP3 inflammasome and inhibit the inflammatory response, some common drugs are useful. PCSK9 inhibitor and statin can both inactivate NLRP3 inflammasome (Wang X. et al., 2020; Chen et al., 2021), while melatonin can downregulate CaMKII in isolated heart I/R injury under intermittent hypoxia condition; by this way, it reduces the release of inflammatory factors like TNF- $\alpha$ and IL-6 (Yeung et al., 2015). During I/R, SGLT2 inhibitors effectively reduce the inflammatory response and the formation of inflammasomes in cardiomyocytes, and the mechanism may be related to the downregulation of CaMKII and the activation of phosphorylated AMPKa by maintaining intracellular ion homeostasis (Andreadou 
et al., 2020). Thus, CaMKII simultaneously activates NLRP3 inflammasomes, induces inflammatory response through the NF$\kappa \mathrm{B}$ inflammatory pathway, and mediates the involvement of immune cells in post-MI remodeling.

\section{Calmodulin-Dependent Protein Kinase II and Necroptosis}

Necroptosis is a newly found cell death mode, which the death cell's morphology resembles between necrosis and apoptosis, and it acts as a critical role in cell survival and diseases (Weinlich et al., 2017). The main pathway in necroptosis includes the inhibition of caspase-8, resulting in activation of receptor-interacting protein (RIP) kinase family activation (RIP1 and RIP3); as two substrates of effector protein mixed lineage kinase domain-like protein (MLKL), it is phosphorylated and oligomerized to perforate the cell membrane (Weinlich et al., 2017). It was found that RIP3, rather than RIP1, activates CaMKII to trigger cardiomyocyte necroptosis by mPTP (Zhang et al., 2016). This study verified that RIP3-induced phosphorylation or oxidative activation of CaMKII triggers the opening of the MPTP and myocardial necrosis in $\mathrm{HF}$ due to $\mathrm{I} / \mathrm{R}$ or doxorubicin (Zhang et al., 2016). Further studies showed that in the ischemic preconditioning of the rat heart, the RIP1 inhibitor NEC-1 and its combination improved the recovery of ischemic cardiac function and reduced the infarction area by preventing MLKL oligomerization and translocation to the membrane. It is suggested that inhibition of necroptosis plays an important role in cardioprotecion in ischemic preconditioning independent of CaMKII signal transduction and oxidative stress (Szobi et al., 2018). Some drugs or inhibitors have effect on the necroptosis pathway in MI or I/R. Melatonin attenuates chronic pain-related MI susceptibility by inhibiting the RIP3-MLKL/CaMKII signaling pathway (Yang et al., 2018), and it can also alleviate endothelial necroptosis by the RIPK3-PGAM5-CypD-mPTP axis in cardiac microvascular I/R injury (Zhou et al., 2018). ZYZ-803, as a compound producing NO and hydrogen sulfide gas, can both alleviate ER stress and necroptosis after MI by suppression of the RIP3-CaMKII pathway (Chang et al., 2019). Adenosine kinase (ADK) inhibitor in I/R injury results in diminishing of CaMKII and MLKL phosphorylation; in addition to stabilizing the $\mathrm{X}$-linked apoptotic protein (XIAP), it inhibits both necroptotic and apoptotic pathways during I/R (Yoo et al., 2009). Bisphenol A upregulates the RIPK3/CaMKII pathway in coronary endothelial cells to decline the integration of artery wall by the necroptotic pathway (Reventun et al., 2020). Necroptosis also occurs in other cardiac injuries such as hyperglycemic myocardial dysfunction (Sun et al., 2019), and it may also provide a new direction in I/R and ischemic cardiomyopathy in the future.

\section{Calmodulin-Dependent Protein Kinase II and Autophagy}

Although autophagy and CaMKII have been studied deeply in neurology and oncology (Jing et al., 2016; Li et al., 2017), they are still less known in myocardial I/R injury. In the mouse HF model, the activation of caspase- 3 could not be detected in a small portion of TUNEL-positive cardiomyocytes. However, autophagic death was only found in approximately $0.3 \%$ of cardiomyocytes in ischemic or dilated cardiomyopathy (Knaapen et al., 2001). Autophagy-induced death was confirmed by cytoplasmic inclusion body called autophagic body. Thus, this group of autophagic cardiomyocytes is characterized by granular cytoplasmic ubiquitin inclusions, but both necrosis and apoptosis markers, like TUNEL stain and caspase- 9 , are negative; meanwhile, caspase- 3 and -7 cleavage are also absent (Knaapen et al., 2001). It was reported that ROS activates the TRPM2-Ca ${ }^{2}{ }^{+}$-CaMKII cascade to phosphorylate Beclin1 on Ser295, thus leading to autophagy inhibition (Wang et al., 2016). However, it remains to be studied whether ROS affects autophagy through related pathways during cardiac I/R. And inhibiting CaMKII by $\mathrm{KN}-93$ in the cardiac remodeling model induced by free fatty acid and hyperlipidemia, the autophagy level is decreased, which demonstrates a potential path to prevent fat-induced myocardial remodeling (Zhong et al., 2017). Recently, research demonstrated that inhibition of CaMKII $\delta$ decreases beclin-1 phosphorylation at Ser90, which reduces myocardial autophagy and I/R damage, while beclin-1 siRNA has little effect on CaMKII phosphorylation (Kong et al., 2020). In addition, CaMKIIסC upregulates the expression of class I histone deacetylase (HDAC) in HF, including HDAC1 and HDAC3, but only HDAC1 inhibitors downregulate the autophagy gene of cardiomyocytes and reduce autophagic death of cardiomyocytes (Zhang et al., 2020). While applying traditional Chinese medicine Panax Notoginseng saponins (PNS), the cardiac function was reserved after MI by phosphorylating CaMKII and its downstream AMPK (Wang D. et al., 2021), which possibly through AMPK/mTOR signaling to activate not only cardiomyocyte but also vascular smooth muscle cell (VSMC) and endothelial cell autophagy (Hughes et al., 2020). Thus, both excessive activation and excessive inhibition of autophagy give rise to cardiomyocyte death, and CaMKII plays a certain role in these processes.

\section{The Role of Calmodulin-Dependent Protein Kinase II and Other Modes of Cardiomyocyte Death}

Ferroptosis (Li et al., 2021), parthanatos, and other cardiomyocyte death forms (Del Re et al., 2019) are also included in a variety of cardiac pathological conditions. Among them, ferroptosis is associated with the accumulation of ion and lipid, which can be induced by erastin (Tang et al., 2019). In diabetic myocardial I/R injury, ER stress leads to ferroptosis of myocardial cells; in addition, inhibition of ferroptosis can reduce the cardiotoxicity in $\mathrm{I} / \mathrm{R}$ and doxorubicin-induced HF (Fang et al., 2019; Li et al., 2020). However, ER stress is closely related to the activation of CaMKII; thus, we speculate that CaMKII activation may lead to ferroptosis of cardiomyocytes through ER stress. Furthermore, parthanatos is featured by hyper-activation of PARP-1 and accumulation of PARP in the cytosol and then leads to DNA fragmentation related by apoptosis-inducing factor (AIF) (Tang et al., 2019). In 2017, it was found that PARP was activated and 
AIF was translocated in circulating leukocyte in chronic HF patients (Bárány et al., 2017). But the relative mechanism and its existence in different cardiac diseases remain to be solved. Therefore, a variety of cell death modes occur during myocardial $\mathrm{I} / \mathrm{R}$ and associate with CaMKII activation (Figure 4).

\section{CALMODULIN-DEPENDENT PROTEIN KINASE II INHIBITION}

Since the first CaMKII inhibitor, KN-62 was invented in experiment (Tokumitsu et al., 1990); more and more drugs targeting CaMKII were discovered. Yet most of drugs are still utilized in animal models, only three specific CaMKII inhibitors, rimacalib (SMP-114), tatCN21 (Zybura et al., 2020), and ranolazine are applied in clinical trials, so there is still a long journey to the development of CaMKII-related medicine and its utilization in myocardial I/R injury. Meanwhile, many commonly used drugs have effect on CaMKII suppression, which is also unfavorable to the passion of targeting CaMKII invention. In this article, we enumerate several CaMKII-specific inhibitors (Table 2) and drugs affecting CaMKII and its related pathway in I/R (Table 3).

\section{CONCLUSION}

Cardiomyocyte $\mathrm{Ca}^{2+}$ overload is a major cause of I/R injury, initiating a cascade of events culminating in cardiomyocyte death and myocardial dysfunction. CaMKII activation is a key feature of

\section{REFERENCES}

Anderson, M. E. (2015). Oxidant Stress Promotes Disease by Activating CaMKII. J. Mol. Cell Cardiol. 89 (Pt B), 160-167. doi:10.1016/j.yjmcc.2015.10.014

Andreadou, I., Bell, R. M., Bøtker, H. E., and Zuurbier, C. J. (2020). SGLT2 Inhibitors Reduce Infarct Size in Reperfused Ischemic Heart and Improve Cardiac Function during Ischemic Episodes in Preclinical Models. Biochim. Biophys. Acta (Bba) - Mol. Basis Dis. 1866 (7), 165770. doi:10.1016/j.bbadis. 2020.165770

Bárány, T., Simon, A., Szabó, G., Benkő, R., Mezei, Z., Molnár, L., et al. (2017). Oxidative Stress-Related Parthanatos of Circulating Mononuclear Leukocytes in Heart Failure. Oxid Med. Cel Longev 2017, 1249614. doi:10.1155/2017/ 1249614

Beauverger, P., Ozoux, M. L., Bégis, G., Glénat, V., Briand, V., Philippo, M. C., et al. (2020). Reversion of Cardiac Dysfunction by a Novel Orally Available Calcium/ calmodulin-dependent Protein Kinase II Inhibitor, RA306, in a Genetic Model of Dilated Cardiomyopathy. Cardiovasc. Res. 116 (2), 329-338. doi:10.1093/cvr/ cvz097

Beckendorf, J., van den Hoogenhof, M. M. G., and Backs, J. (2018). Physiological and Unappreciated Roles of CaMKII in the Heart. Basic Res. Cardiol. 113 (4), 29. doi:10.1007/s00395-018-0688-8

Boontje, N. M., Merkus, D., Zaremba, R., Versteilen, A., de Waard, M. C., et al. (2011). Enhanced Myofilament Responsiveness upon $\beta$-adrenergic Stimulation in post-infarct Remodeled Myocardium. J. Mol. Cell Cardiol. 50 (3), 487-499. doi:10.1016/j.yjmcc.2010.12.002

Chang, L., Wang, Z., Ma, F., Tran, B., Zhong, R., Xiong, Y., et al. (2019). ZYZ-803 Mitigates Endoplasmic Reticulum Stress-Related Necroptosis after Acute Myocardial Infarction through Downregulating the RIP3-CaMKII Signaling Pathway. Oxid Med. Cel Longev 2019, 6173685. doi:10.1155/2019/6173685 myocardial I/R, leading to adverse reactions such as intracellular mitochondrial swelling, $\mathrm{ER} \mathrm{Ca}^{2+}$ leak, and abnormal contraction of myofilaments. CaMKII $\delta$ has been widely studied in the activation, localization, signaling pathways, and induced cell death of cardiomyocytes. Although the utilization of CaMKII inhibitor has not been carried out on a large scale in clinical work, many teams have made a great deal of contributions to relevant studies, and based on this theoretical basis, new targets and feasible inhibitors of related pathways have been sought. Understanding of CaMKII mode of action in cardiomyocytes death induced by $\mathrm{I} / \mathrm{R}$ is helpful to ameliorate treatment strategies and find out new targets of CaMKII applied to new therapy. We anticipate that there will be several promising treatment regiments or drugs to correct abnormal activation of CAMKII in the future for I/R injury after $\mathrm{MI}$ and other related cardiac diseases.

\section{AUTHOR CONTRIBUTIONS}

YX designed the study; YX, YY, KJ, MQ, and XL wrote and revised the manuscripts.

\section{FUNDING}

This work was supported by the National Outstanding Youth Science Fund Project of National Natural Science Foundation of China (81822048) and Fundamental Research Funds for the Central Universities (22120200064).

Chen, A., Chen, Z., Zhou, Y., Wu, Y., Xia, Y., Lu, D., et al. (2021). Rosuvastatin Protects against Coronary Microembolization-Induced Cardiac Injury via Inhibiting NLRP3 Inflammasome Activation. Cell Death Dis 12 (1), 78. doi:10.1038/s41419-021-03389-1

Cook, S. G., Buonarati, O. R., Coultrap, S. J., and Bayer, K. U. (2021). CaMKII Holoenzyme Mechanisms that Govern the LTP versus LTD Decision. Sci. Adv. 7 (16), eabe2300. doi:10.1126/sciadv.abe2300

Coultrap, S. J., and Bayer, K. U. (2014). Nitric Oxide Induces Ca2+-independent Activity of the Ca2+/calmodulin-dependent Protein Kinase II (CaMKII). J. Biol. Chem. 289 (28), 19458-19465. doi:10.1074/jbc.m114.558254

Curran, J., Tang, L., Roof, S. R., Velmurugan, S., Millard, A., Shonts, S., et al. (2014). Nitric Oxide-dependent Activation of CaMKII Increases Diastolic Sarcoplasmic Reticulum Calcium Release in Cardiac Myocytes in Response to Adrenergic Stimulation. PLoS One 9 (2), e87495. doi:10.1371/journal.pone.0087495

Cutler, M. J., Plummer, B. N., Wan, X., Sun, Q.-A., Hess, D., Liu, H., et al. (2012). Aberrant S-Nitrosylation Mediates Calcium-Triggered Ventricular Arrhythmia in the Intact Heart. Proc. Natl. Acad. Sci. 109 (44), 18186-18191. doi:10.1073/ pnas. 1210565109

Daniels, L., Bell, J. R., Delbridge, L. M. D., McDonald, F. J., Lamberts, R. R., and Erickson, J. R. (2015). The Role of CaMKII in Diabetic Heart Dysfunction. Heart Fail. Rev. 20 (5), 589-600. doi:10.1007/s10741-015-9498-3

Daniels, L. J., Wallace, R. S., Nicholson, O. M., Wilson, G. A., McDonald, F. J., Jones, P. P., et al. (2018). Inhibition of Calcium/calmodulin-dependent Kinase II Restores Contraction and Relaxation in Isolated Cardiac Muscle from Type 2 Diabetic Rats. Cardiovasc. Diabetol. 17 (1), 89. doi:10.1186/s12933-018-0732-x Dassanayaka, S., and Jones, S. P. (2014). O-GlcNAc and the Cardiovascular System. Pharmacol. Ther. 142 (1), 62-71. doi:10.1016/j.pharmthera.2013.11.005

Del Re, D. P., Amgalan, D., Linkermann, A., Liu, Q., and Kitsis, R. N. (2019). Fundamental Mechanisms of Regulated Cell Death and Implications for Heart Disease. Physiol. Rev. 99 (4), 1765-1817. doi:10.1152/physrev.00022.2018 
Dewenter, M., Neef, S., Vettel, C., Lämmle, S., Beushausen, C., Zelarayan, L. C., et al. (2017). Calcium/Calmodulin-Dependent Protein Kinase II Activity Persists during Chronic $\beta$-Adrenoceptor Blockade in Experimental and Human Heart Failure. Circ. Heart Fail. 10 (5), e003840. doi:10.1161/ circheartfailure.117.003840

Di Carlo, M. N., Said, M., Ling, H., Valverde, C. A., De Giusti, V. C., et al. (2014). CaMKII-dependent Phosphorylation of Cardiac Ryanodine Receptors Regulates Cell Death in Cardiac Ischemia/reperfusion Injury. J. Mol. Cell Cardiol. 74, 274-283. doi:10.1016/j.yjmcc.2014.06.004

El Refaey, M., Musa, H., Murphy, N. P., Lubbers, E. R., Skaf, M., Han, M., et al. (2019). Protein Phosphatase 2A Regulates Cardiac Na + Channels. Circ. Res. 124 (5), 737-746. doi:10.1161/circresaha.118.314350

Erickson, J. R., He, B. J., Grumbach, I. M., and Anderson, M. E. (2011). CaMKII in the Cardiovascular System: Sensing Redox States. Physiol. Rev. 91 (3), 889-915. doi:10.1152/physrev.00018.2010

Erickson, J. R., Joiner, M.-1. A., Guan, X., Kutschke, W., Yang, J., Oddis, C. V., et al. (2008). A Dynamic Pathway for Calcium-independent Activation of CaMKII by Methionine Oxidation. Cell 133 (3), 462-474. doi:10.1016/j.cell.2008.02.048

Erickson, J. R., Nichols, C. B., Uchinoumi, H., Stein, M. L., Bossuyt, J., and Bers, D. M. (2015). S-nitrosylation Induces Both Autonomous Activation and Inhibition of Calcium/Calmodulin-dependent Protein Kinase II $\delta$. J. Biol. Chem. 290 (42), 25646-25656. doi:10.1074/jbc.m115.650234

Erickson, J. R., Pereira, L., Wang, L., Han, G., Ferguson, A., Dao, K., et al. (2013). Diabetic Hyperglycaemia Activates CaMKII and Arrhythmias by O-Linked Glycosylation. Nature 502 (7471), 372-376. doi:10.1038/nature12537

Fang, X., Wang, H., Han, D., Xie, E., Yang, X., Wei, J., et al. (2019). Ferroptosis as a Target for protection against Cardiomyopathy. Proc. Natl. Acad. Sci. USA 116 (7), 2672-2680. doi:10.1073/pnas.1821022116

Fischer, T. H., Eiringhaus, J., Dybkova, N., Saadatmand, A., Pabel, S., Weber, S., et al. (2018). Activation of Protein Phosphatase 1 by a Selective Phosphatase Disrupting Peptide Reduces Sarcoplasmic Reticulum Ca 2+ Leak in Human Heart Failure. Eur. J. Heart Fail. 20 (12), 1673-1685. doi:10. 1002/ejhf.1297

Garcia-Dorado, D., Ruiz-Meana, M., Inserte, J., Rodriguez-Sinovas, A., and Piper, H. M. (2012). Calcium-mediated Cell Death during Myocardial Reperfusion. Cardiovasc. Res. 94 (2), 168-180. doi:10.1093/cvr/cvs116

Gray, C. B. B., and Heller Brown, J. (2014). CaMKIIdelta Subtypes: Localization and Function. Front. Pharmacol. 5, 15. doi:10.3389/fphar.2014.00015

Gray, C. B. B., Suetomi, T., Xiang, S., Mishra, S., Blackwood, E. A., Glembotski, C. C., et al. (2017). CaMKII $\delta$ Subtypes Differentially Regulate Infarct Formation Following ex vivo Myocardial Ischemia/reperfusion through NF- $\kappa B$ and TNF- $\alpha$. J. Mol. Cell. Cardiol. 103, 48-55. doi:10.1016/j.yjmcc.2017.01.002

Gui, L., Guo, X., Zhang, Z., Xu, H., Ji, Y.-W., Wang, R.-J., et al. (2018). Activation of CaMKIISA Promotes Ca2+ Leak from the Sarcoplasmic Reticulum in Cardiomyocytes of Chronic Heart Failure Rats. Acta Pharmacol. Sin 39 (10), 1604-1612. doi:10.1038/aps.2018.20

Gutierrez, D. A., Fernandez-Tenorio, M., Ogrodnik, J., and Niggli, E. (2013). NOdependent CaMKII Activation during $\beta$-adrenergic Stimulation of Cardiac Muscle. Cardiovasc. Res. 100 (3), 392-401. doi:10.1093/cvr/cvt201

Hausenloy, D. J., and Yellon, D. M. (2013). Myocardial Ischemia-Reperfusion Injury: a Neglected Therapeutic Target. J. Clin. Invest. 123 (1), 92. doi:10.1172/ jci62874

Hausenloy, D. J., and Yellon, D. M. (2008). Time to Take Myocardial Reperfusion Injury Seriously. N. Engl. J. Med. 359 (5), 518-520. doi:10.1056/nejme0803746

He, B. J., Joiner, M.-L. A., Singh, M. V., Luczak, E. D., Swaminathan, P. D., Koval, O. M., et al. (2011). Oxidation of CaMKII Determines the Cardiotoxic Effects of Aldosterone. Nat. Med. 17 (12), 1610-1618. doi:10.1038/nm.2506

He, Y., Hara, H., and Núñez, G. (2016). Mechanism and Regulation of NLRP3 Inflammasome Activation. Trends Biochem. Sci. 41 (12), 1012-1021. doi:10. 1016/j.tibs.2016.09.002

Hegyi, B., Borst, J. M., Bailey, L. R. J., Shen, E. Y., Lucena, A. J., Navedo, M. F., et al. (2020). Hyperglycemia Regulates Cardiac K Channels via O-GlcNAc-CaMKII and NOX2-ROS-PKC Pathways. Basic Res. Cardiol. 115 (6), 71. doi:10.1007/ s00395-020-00834-8

Heist, E. K., Srinivasan, M., and Schulman, H. (1998). Phosphorylation at the Nuclear Localization Signal of Ca2+/calmodulin-dependent Protein Kinase II blocks its Nuclear Targeting. J. Biol. Chem. 273 (31), 19763-19771. doi:10.1074/ jbc.273.31.19763
Heusch, G. (2020). Myocardial Ischaemia-Reperfusion Injury and Cardioprotection in Perspective. Nat. Rev. Cardiol. 17 (12), 773-789. doi:10. 1038/s41569-020-0403-y

Howard, T., Greer-Short, A., Satroplus, T., Patel, N., Nassal, D., Mohler, P. J., et al. (2018). CaMKII-dependent Late Na+current Increases Electrical Dispersion and Arrhythmia in Ischemia-Reperfusion. Am. J. Physiology-Heart Circulatory Physiol. 315 (4), H794-H801. doi:10.1152/ajpheart.00197.2018

Hughes, W. E., Beyer, A. M., and Gutterman, D. D. (2020). Vascular Autophagy in Health and Disease. Basic Res. Cardiol. 115 (4), 41. doi:10.1007/s00395-020$0802-6$

Hund, T. J., Decker, K. F., Kanter, E., Mohler, P. J., Boyden, P. A., Schuessler, R. B., et al. (2008). Role of Activated CaMKII in Abnormal Calcium Homeostasis and INa Remodeling after Myocardial Infarction: Insights from Mathematical Modeling. J. Mol. Cell Cardiol. 45 (3), 420-428. doi:10.1016/j.yjmcc.2008.06.007

Hund, T. J., Koval, O. M., Li, J., Wright, P. J., Qian, L., Snyder, J. S., et al. (2010). A $\beta I V$-spectrin/CaMKII Signaling Complex Is Essential for Membrane Excitability in Mice. J. Clin. Invest. 120 (10), 3508-3519. doi:10.1172/jci43621

Jing, Z., Sui, X., Yao, J., Xie, J., Jiang, L., Zhou, Y., et al. (2016). SKF-96365 Activates Cytoprotective Autophagy to Delay Apoptosis in Colorectal Cancer Cells through Inhibition of the calcium/CaMKII $\gamma /$ AKT-Mediated Pathway. Cancer Lett. 372 (2), 226-238. doi:10.1016/j.canlet.2016.01.006

Joiner, M.-L. A., Koval, O. M., Li, J., He, B. J., Allamargot, C., Gao, Z., et al. (2012). CaMKII Determines Mitochondrial Stress Responses in Heart. Nature 491 (7423), 269-273. doi:10.1038/nature11444

Kajstura, J., Cheng, W., Reiss, K., Clark, W. A., Sonnenblick, E. H., Krajewski, S., et al. (1996). Apoptotic and Necrotic Myocyte Cell Deaths Are Independent Contributing Variables of Infarct Size in Rats. Lab. Invest. 74 (1), 86-107.

Ke, H. Y., Chin, L. H., Tsai, C. S., Lin, F. Z., Chen, Y. H., Chang, Y. L., et al. (2020). Cardiac Calcium Dysregulation in Mice with Chronic Kidney Disease. J. Cel Mol Med 24 (6), 3669-3677. doi:10.1111/jcmm.15066

Knaapen, M. W. M., Davies, M. J., De Bie, M., Haven, A. J., Martinet, W., and Kockx, M. M. (2001). Apoptotic versus Autophagic Cell Death in Heart Failure. Cardiovasc. Res. 51 (2), 304-312. doi:10.1016/s0008-6363(01)00290-5

Kong, L., Xiong, F., Sun, N., Xu, C., Chen, Y., Yang, J., et al. (2020). CaMKII $\delta$ Inhibition Protects against Myocardial Ischemia/reperfusion Injury: Role of Beclin-1-dependent Autophagy. Eur. J. Pharmacol. 886, 173539. doi:10.1016/j. ejphar.2020.173539

Lagerlöf, O., Slocomb, J. E., Hong, I., Aponte, Y., Blackshaw, S., Hart, G. W., et al. (2016). The Nutrient Sensor OGT in PVN Neurons Regulates Feeding. Science 351 (6279), 1293-1296. doi:10.1126/science.aad5494

Le, D. E., Davis, C. M., Wei, K., Zhao, Y., Cao, Z., Nugent, M., et al. (2020). Ranolazine May Exert its beneficial Effects by Increasing Myocardial Adenosine Levels. Am. J. Physiology-Heart Circulatory Physiol. 318 (1), H189-H202. doi:10.1152/ajpheart.00217.2019

Lee, H. W., Ahmad, M., Weldrick, J. J., Wang, H.-W., Burgon, P. G., and Leenen, F. H. H. (2018). Effects of Exercise Training and TrkB blockade on Cardiac Function and BDNF-TrkB Signaling Postmyocardial Infarction in Rats. Am. J. Physiology-Heart Circulatory Physiol. 315 (6), H1821-H1834. doi:10.1152/ ajpheart.00245.2018

Li, N., Jiang, W., Wang, W., Xiong, R., Wu, X., and Geng, Q. (2021). Ferroptosis and its Emerging Roles in Cardiovascular Diseases. Pharmacol. Res. 166, 105466. doi:10.1016/j.phrs.2021.105466

Li, W., Li, W., Leng, Y., Xiong, Y., and Xia, Z. (2020). Ferroptosis Is Involved in Diabetes Myocardial Ischemia/Reperfusion Injury through Endoplasmic Reticulum Stress. DNA Cel Biol. 39 (2), 210-225. doi:10.1089/dna.2019.5097

Li, X., Wu, X.-Q., Deng, R., Li, D.-D., Tang, J., Chen, W.-D., et al. (2017). CaMKIImediated Beclin 1 Phosphorylation Regulates Autophagy that Promotes Degradation of Id and Neuroblastoma Cell Differentiation. Nat. Commun. 8 (1), 1159. doi:10.1038/s41467-017-01272-2

Ling, H., Gray, C. B. B., Zambon, A. C., Grimm, M., Gu, Y., Dalton, N., et al. (2013). Ca $2+/$ Calmodulin-dependent Protein Kinase II $\delta$ Mediates Myocardial Ischemia/Reperfusion Injury through Nuclear Factor- $\mathrm{BB}$. Circ. Res. 112 (6), 935-944. doi:10.1161/circresaha.112.276915

Liu, T., Wang, Q., and Yao, K. (2020). Huoxue Wentong Formula Ameliorates Myocardial Infarction in Rats through Inhibiting CaMKII Oxidation and Phosphorylation. Chin. Med. 15, 3. doi:10.1186/s13020-020-0285-2

Ljubojevic-Holzer, S., Herren, A. W., Djalinac, N., Voglhuber, J., Morotti, S., Holzer, M., et al. (2020). CaMKIISC Drives Early Adaptive Ca 2+ Change and 
Late Eccentric Cardiac Hypertrophy. Circ. Res. 127 (9), 1159-1178. doi:10. 1161/circresaha.120.316947

Lu, H. T., Feng, R. Q., Tang, J. K., Zhou, J. J., Gao, F., and Ren, J. (2020). CaMKII/ calpain Interaction Mediates Ischemia/reperfusion Injury in Isolated Rat Hearts. Cel Death Dis 11 (5), 388. doi:10.1038/s41419-020-2605-y

Luo, H., Song, S., Chen, Y., Xu, M., Sun, L., Meng, G., et al. (2019). Inhibitor 1 of Protein Phosphatase 1 Regulates Ca/Calmodulin-dependent Protein Kinase II to Alleviate Oxidative Stress in Hypoxia-Reoxygenation Injury of Cardiomyocytes. Oxid Med. Cel Longev 2019, 2193019. doi:10.1155/2019/ 2193019

Luo, M., Guan, X., Luczak, E. D., Lang, D., Kutschke, W., Gao, Z., et al. (2013). Diabetes Increases Mortality after Myocardial Infarction by Oxidizing CaMKII. J. Clin. Invest. 123 (3), 1262-1274. doi:10.1172/jci65268

Ma, Y., Cheng, W., Wu, S., and Wong, T. (2009). Oestrogen Confers Cardioprotection by Suppressing $\mathrm{Ca} 2+/$ calmodulin-dependent Protein Kinase II. Br. J. Pharmacol. 157 (5), 705-715. doi:10.1111/j.1476-5381.2009. 00212.x

Manninger, M., Zweiker, D., Dobrovnik, M., van Hunnik, A., Rohrer, U., Zirngast, B., et al. (2020). Acute Hyperglycaemia Is Not Associated with the Development of Atrial Fibrillation in Healthy Pigs. Sci. Rep. 10 (1), 11881. doi:10.1038/ s41598-020-68897-0

Mattiazzi, A., Vittone, L., and Mundiña-Weilenmann, C. (2007). Ca2+/ calmodulin-dependent Protein Kinase: a Key Component in the Contractile Recovery from Acidosis. Cardiovasc. Res. 73 (4), 648-656. doi:10.1016/j. cardiores.2006.12.002

Mayford, M., Bach, M. E., Huang, Y.-Y., Wang, L., Hawkins, R. D., and Kandel, E. R. (1996). Control of Memory Formation through Regulated Expression of a CaMKII Transgene. Science 274 (5293), 1678-1683. doi:10.1126/science.274. 5293.1678

Mesubi, O. O., Rokita, A. G., Abrol, N., Wu, Y., Chen, B., Wang, Q., et al. (2021). Oxidized CaMKII and O-GlcNAcylation Cause Increased Atrial Fibrillation in Diabetic Mice by Distinct Mechanisms. J. Clin. Invest. 131 (2), e95747. doi:10. 1172/jci95747

Mishra, S., Gray, C. B. B., Miyamoto, S., Bers, D. M., and Brown, J. H. (2011). Location Matters. Circ. Res. 109 (12), 1354-1362. doi:10.1161/circresaha.111. 248401

Miura, M., Handoh, T., Taguchi, Y., Hasegawa, T., Takahashi, Y., Morita, N., et al. (2020). Transient Elevation of Glucose Increases Arrhythmia Susceptibility in Non-diabetic Rat Trabeculae with Non-uniform Contraction. Circ. J. 84 (4), 551-558. doi:10.1253/circj.cj-19-0715

Morgan, M. J., and Liu, Z.-g. (2011). Crosstalk of Reactive Oxygen Species and NFкB Signaling. Cell Res 21 (1), 103-115. doi:10.1038/cr.2010.178

Munevar, S., Gangopadhyay, S. S., Gallant, C., Colombo, B., Sellke, F. W., and Morgan, K. G. (2008). CaMKIIT287 and T305 Regulate History-dependent Increases in Alpha Agonist-Induced Vascular Tone. J. Cel Mol Med 12 (1), 219-226. doi:10.1111/j.1582-4934.2007.00202.x

Murakoshi, H., Shin, M. E., Parra-Bueno, P., Szatmari, E. M., Shibata, A. C. E., and Yasuda, R. (2017). Kinetics of Endogenous CaMKII Required for Synaptic Plasticity Revealed by Optogenetic Kinase Inhibitor. Neuron 94 (1), 37. doi:10. 1016/j.neuron.2017.04.027

Mustroph, J., Drzymalski, M., Baier, M., Pabel, S., Biedermann, A., Memmel, B., et al. (2020). The Oral Ca/calmodulin-dependent Kinase II Inhibitor RA608 Improves Contractile Function and Prevents Arrhythmias in Heart Failure. ESC Heart Fail. 7 (5), 2871-2883. doi:10.1002/ehf2.12895

Neef, S., Mann, C., Zwenger, A., Dybkova, N., and Maier, L. S. (2017). Reduction of SR Ca Leak and Arrhythmogenic Cellular Correlates by SMP-114, a Novel CaMKII Inhibitor with Oral bioavailability. Basic Res. Cardiol. 112 (4), 45. doi:10.1007/s00395-017-0637-y

Netticadan, T., Temsah, R. M., Kawabata, K., and Dhalla, N. S. (2000). Sarcoplasmic Reticulum Ca2+/Calmodulin-dependent Protein Kinase Is Altered in Heart Failure. Circ. Res. 86 (5), 596-605. doi:10.1161/01.res.86.5.596

Ngoh, G. A., Facundo, H. T., Zafir, A., and Jones, S. P. (2010). O -GlcNAc Signaling in the Cardiovascular System. Circ. Res. 107 (2), 171-185. doi:10.1161/ circresaha.110.224675

Pereira, L., Cheng, H., Lao, D. H., Na, L., van Oort, R. J., Brown, J. H., et al. (2013). Epac2 Mediates Cardiac $\beta 1$-Adrenergic-Dependent Sarcoplasmic Reticulum Ca 2+ Leak and Arrhythmia. Circulation 127 (8), 913-922. doi:10.1161/ circulationaha.12.148619
Pezhouman, A., Singh, N., Song, Z., Nivala, M., Eskandari, A., Cao, H., et al. (2015). Molecular Basis of Hypokalemia-Induced Ventricular Fibrillation. Circulation 132 (16), 1528-1537. doi:10.1161/circulationaha.115.016217

Prabhakaran, D., Anand, S., Watkins, D., Gaziano, T., Wu, Y., Mbanya, J. C., et al. (2018). Cardiovascular, Respiratory, and Related Disorders: Key Messages from Disease Control Priorities, 3rd Edition. Lancet 391 (10126), 1224-1236. doi:10. 1016/S0140-6736(17)32471-6

Reil, J. C., Reil, G. H., Kovács, Á., Sequeira, V., Waddingham, M. T., Lodi, M., et al. (2020). CaMKII Activity Contributes to Homeometric Autoregulation of the Heart: A Novel Mechanism for the Anrep Effect. J. Physiol. 598 (15), 3129-3153. doi:10.1113/jp279607

Reventun, P., Sanchez-Esteban, S., Cook, A., Cuadrado, I., Roza, C., MorenoGomez-Toledano, R., et al. (2020). Bisphenol A Induces Coronary Endothelial Cell Necroptosis by Activating RIP3/CamKII Dependent Pathway. Sci. Rep. 10 (1), 4190. doi:10.1038/s41598-020-61014-1

Rokita, A. G., and Anderson, M. E. (2012). New Therapeutic Targets in Cardiology. Circulation 126 (17), 2125-2139. doi:10.1161/circulationaha.112.124990

Salas, M. A., Valverde, C. A., Sánchez, G., Said, M., Rodriguez, J. S., Portiansky, E. L., et al. (2010). The Signalling Pathway of CaMKII-Mediated Apoptosis and Necrosis in the Ischemia/reperfusion Injury. J. Mol. Cell. Cardiol. 48 (6), 1298-1306. doi:10.1016/j.yjmcc.2009.12.015

Sheng, J.-J., Chang, H., and Yu, Z.-B. (2015). Nuclear Translocation of Calpain-2 Mediates Apoptosis of Hypertrophied Cardiomyocytes in Transverse Aortic Constriction Rat. J. Cel. Physiol. 230 (11), 2743-2754. doi:10.1002/jcp.24999

Shi, J., Gao, W., and Shao, F. (2017). Pyroptosis: Gasdermin-Mediated Programmed Necrotic Cell Death. Trends Biochem. Sci. 42 (4), 245-254. doi:10.1016/j.tibs.2016.10.004

Singh, M. V., Swaminathan, P. D., Luczak, E. D., Kutschke, W., Weiss, R. M., and Anderson, M. E. (2012). MyD88 Mediated Inflammatory Signaling Leads to CaMKII Oxidation, Cardiac Hypertrophy and Death after Myocardial Infarction. J. Mol. Cell. Cardiol. 52 (5), 1135-1144. doi:10.1016/j.yjmcc.2012.01.021

Srinivasan, M., Edman, C. F., and Schulman, H. (1994). Alternative Splicing Introduces a Nuclear Localization Signal that Targets Multifunctional CaM Kinase to the Nucleus. J. Cel Biol 126 (4), 839-852. doi:10.1083/jcb.126.4.839

Strack, S., Barban, M. A., Wadzinski, B. E., and Colbran, R. J. (1997). Differential Inactivation of Postsynaptic Density-Associated and Soluble Ca2+/calmodulindependent Protein Kinase II by Protein Phosphatases 1 and 2A. J. Neurochem. 68 (5), 2119-2128. doi:10.1046/j.1471-4159.1997.68052119.x

Suetomi, T., Miyamoto, S., and Brown, J. H. (2019). Inflammation in Nonischemic Heart Disease: Initiation by Cardiomyocyte CaMKII and NLRP3 Inflammasome Signaling. Am. J. Physiology-Heart Circulatory Physiol. 317 (5), H877-H890. doi:10.1152/ajpheart.00223.2019

Suetomi, T., Willeford, A., Brand, C. S., Cho, Y., Ross, R. S., Miyamoto, S., et al. (2018). Inflammation and NLRP3 Inflammasome Activation Initiated in Response to Pressure Overload by $\mathrm{Ca}$ 2+/Calmodulin-dependent Protein Kinase II $\delta$ Signaling in Cardiomyocytes Are Essential for Adverse Cardiac Remodeling. Circulation 138 (22), 2530-2544. doi:10.1161/circulationaha.118.034621

Sun, L., Chen, Y., Luo, H., Xu, M., Meng, G., and Zhang, W. (2019). Ca2+/ calmodulin-dependent Protein Kinase II Regulation by Inhibitor 1 of Protein Phosphatase 1 Alleviates Necroptosis in High Glucose-Induced Cardiomyocytes Injury. Biochem. Pharmacol. 163, 194-205. doi:10.1016/j.bcp.2019.02.022

Swaminathan, P. D., Purohit, A., Soni, S., Voigt, N., Singh, M. V., Glukhov, A. V., et al. (2011). Oxidized CaMKII Causes Cardiac Sinus Node Dysfunction in Mice. J. Clin. Invest. 121 (8), 3277-3288. doi:10.1172/jci57833

Szobi, A., Farkašová-Ledvényiová, V., Lichý, M., Muráriková, M., Čarnická, S., Ravingerová, T., et al. (2018). Cardioprotection of Ischaemic Preconditioning Is Associated with Inhibition of Translocation ofMLKLwithin the Plasma Membrane. J. Cel. Mol. Med. 22 (9), 4183-4196. doi:10.1111/jcmm.13697

Talukder, M. A. H., Zweier, J. L., and Periasamy, M. (2009). Targeting Calcium Transport in Ischaemic Heart Disease. Cardiovasc. Res. 84 (3), 345-352. doi:10. 1093/cvr/cvp264

Tang, D., Kang, R., Berghe, T. V., Vandenabeele, P., and Kroemer, G. (2019). The Molecular Machinery of Regulated Cell Death. Cel Res 29 (5), 347-364. doi:10. 1038/s41422-019-0164-5

Tao, B., Liu, Z., Wei, F., Fan, S., Cui, S., Xia, H., et al. (2020). Over-expression of Kv4.3 Gene Reverses Cardiac Remodeling and Transient-Outward K+ Current (Ito) Reduction via CaMKII Inhibition in Myocardial Infarction. Biomed. Pharmacother. 132, 110896. doi:10.1016/j.biopha.2020.110896 
Tao-Cheng, J.-H., Yang, Y., Bayer, K. U., Reese, T. S., and Dosemeci, A. (2013). Effects of CaMKII Inhibitor tatCN21 on Activity-dependent Redistribution of CaMKII in Hippocampal Neurons. Neuroscience 244, 188-196. doi:10.1016/j. neuroscience.2013.03.063

Tinaquero, D., Crespo-García, T., Utrilla, R. G., Nieto-Marín, P., González-Guerra, A., Rubio-Alarcón, M., et al. (2020). The p.P888L SAP97 Polymorphism Increases the Transient Outward Current (I) and Abbreviates the Action Potential Duration and the QT Interval. Sci. Rep. 10 (1), 10707. doi:10.1038/s41598-020-67109-z

Toischer, K., Rokita, A. G., Unsöld, B., Zhu, W., Kararigas, G., Sossalla, S., et al. (2010). Differential Cardiac Remodeling in Preload versus Afterload. Circulation 122 (10), 993. doi:10.1161/circulationaha.110.943431

Tokumitsu, H., Chijiwa, T., Hagiwara, M., Mizutani, A., Terasawa, M., and Hidaka, H. (1990). KN-62, 1-[N,O-bis(5-isoquinolinesulfonyl)-N-methyl-L-tyrosyl]-4phenylpiperazi Ne, a Specific Inhibitor of $\mathrm{Ca} 2+/$ calmodulin-dependent Protein Kinase II. J. Biol. Chem. 265 (8), 4315-4320. doi:10.1016/s0021-9258(19)39565-1

Uemura, A., Naito, Y., and Matsubara, T. (2002). Dynamics of Ca(2+)/calmodulindependent Protein Kinase II Following Acute Myocardial IschemiaTranslocation and Autophosphorylation. Biochem. Biophys. Res. Commun. 297 (4), 997. doi:10.1016/s0006-291x(02)02279-9

Vila-Petroff, M., Salas, M. A., Said, M., Valverde, C. A., Sapia, L., Portiansky, E., et al. (2007). CaMKII Inhibition Protects against Necrosis and Apoptosis in Irreversible Ischemia-Reperfusion Injury. Cardiovasc. Res. 73 (4), 689-698. doi:10.1016/j.cardiores.2006.12.003

Wang, D., Hu, X., Lee, S. H., Chen, F., Jiang, K., Tu, Z., et al. (2018). Diabetes Exacerbates Myocardial Ischemia/Reperfusion Injury by Down-Regulation of MicroRNA and Up-Regulation of O-GlcNAcylation. JACC: Basic Translational Sci. 3 (3), 350-362. doi:10.1016/j.jacbts.2018.01.005

Wang, D., Lv, L., Xu, Y., Jiang, K., Chen, F., Qian, J., et al. (2021). Cardioprotection of Panax Notoginseng Saponins against Acute Myocardial Infarction and Heart Failure through Inducing Autophagy. Biomed. Pharmacother. 136, 111287. doi:10.1016/j.biopha.2021.111287

Wang, J., Cheng, X., Zhao, H., Yang, Q., and Xu, Z. (2020c). Downregulation of the Zinc Transporter SLC39A13 (ZIP13) Is Responsible for the Activation of CaMKII at Reperfusion and Leads to Myocardial Ischemia/reperfusion Injury in Mouse Hearts. J. Mol. Cel Cardiol 152, 69-79. doi:10.1016/j.yjmcc. 2020.12.002

Wang, J., Cheng, X., Zhao, H., Yang, Q., and Xu, Z. (2021). Downregulation of the Zinc Transporter SLC39A13 (ZIP13) Is Responsible for the Activation of CaMKII at Reperfusion and Leads to Myocardial Ischemia/reperfusion Injury in Mouse Hearts. J. Mol. Cell. Cardiol. 152, 69-79. doi:10.1016/j.yjmcc.2020.12.002

Wang, J., Toan, S., and Zhou, H. (2020a). Mitochondrial Quality Control in Cardiac Microvascular Ischemia-Reperfusion Injury: New Insights into the Mechanisms and Therapeutic Potentials. Pharmacol. Res. 156, 104771. doi:10. 1016/j.phrs.2020.104771

Wang, J., Toan, S., and Zhou, H. (2020b). New Insights into the Role of Mitochondria in Cardiac Microvascular Ischemia/reperfusion Injury. Angiogenesis 23 (3), 299-314. doi:10.1007/s10456-020-09720-2

Wang, J., and Zhou, H. (2020). Mitochondrial Quality Control Mechanisms as Molecular Targets in Cardiac Ischemia-Reperfusion Injury. Acta Pharmaceutica Sinica B 10 (10), 1866-1879. doi:10.1016/j.apsb.2020.03.004

Wang, Q., Guo, W., Hao, B., Shi, X., Lu, Y., Wong, C. W. M., et al. (2016). Mechanistic Study of TRPM2-Ca2+-CAMK2-BECN1 Signaling in Oxidative Stress-Induced Autophagy Inhibition. Autophagy 12 (8), 1340-1354. doi:10. 1080/15548627.2016.1187365

Wang, W., Zhang, H., Gao, H., Kubo, H., Berretta, R. M., Chen, X., et al. (2010). $\beta 1-$ Adrenergic Receptor Activation Induces Mouse Cardiac Myocyte Death through both L-type Calcium Channel-dependent and -independent Pathways. Am. J. Physiology-Heart Circulatory Physiol. 299 (2), H322-H331. doi:10.1152/ajpheart.00392.2010

Wang, X., Li, X., Liu, S., Brickell, A. N., Zhang, J., Wu, Z., et al. (2020). PCSK9 Regulates Pyroptosis via mtDNA Damage in Chronic Myocardial Ischemia. Basic Res. Cardiol. 115 (6), 66. doi:10.1007/s00395-020-00832-w

Wang, Y., Wang, Y., Yang, D., Yu, X., Li, H., Lv, X., et al. (2015). $\beta_{1}$-adrenoceptor Stimulation Promotes LPS-Induced Cardiomyocyte Apoptosis through Activating PKA and Enhancing CaMKII and IкBa Phosphorylation. Crit. Care 19, 76. doi:10.1186/s13054-015-0820-1

Watson, L. J., Facundo, H. T., Ngoh, G. A., Ameen, M., Brainard, R. E., Lemma, K. M., et al. (2010). O-linked $\beta$-N-acetylglucosamine Transferase Is Indispensable in the Failing Heart. Proc. Natl. Acad. Sci. USA 107 (41), 17797-17802. doi:10. 1073/pnas.1001907107

Weinlich, R., Oberst, A., Beere, H. M., and Green, D. R. (2017). Necroptosis in Development, Inflammation and Disease. Nat. Rev. Mol. Cel Biol 18 (2), 127-136. doi:10.1038/nrm.2016.149

Weinreuter, M., Kreusser, M. M., Beckendorf, J., Schreiter, F. C., Leuschner, F., Lehmann, L. H., et al. (2014). Ca M Kinase II Mediates Maladaptive post-infarct Remodeling and Proinflammatory Chemoattractant Signaling but Not Acute Myocardial Ischemia/ reperfusion Injury. EMBO Mol. Med. 6 (10), 1231-1245. doi:10.15252/emmm.201403848

Westra, J., Brouwer, E., Bouwman, E., Doornbos-van der Meer, B., Posthumus, M. D., van Leeuwen, M. A., et al. (2009). Role for CaMKII Inhibition in Rheumatoid Arthritis. Ann. N. Y Acad. Sci. 1173, 706-711. doi:10.1111/j. 1749-6632.2009.04736.x

Willeford, A., Suetomi, T., Nickle, A., Hoffman, H. M., Miyamoto, S., and Heller Brown, J. (2018). CaMKII $\delta$-mediated Inflammatory Gene Expression and Inflammasome Activation in Cardiomyocytes Initiate Inflammation and Induce Fibrosis. JCI Insight 3 (12), e97054. doi:10.1172/jci.insight.97054

Woodman, O. L., Long, R., Pons, S., Eychenne, N., Berdeaux, A., and Morin, D. (2014). The Cardioprotectant $3^{\prime}, 4^{\prime}$-dihydroxyflavonol Inhibits Opening of the Mitochondrial Permeability Transition Pore after Myocardial Ischemia and Reperfusion in Rats. Pharmacol. Res. 81, 26-33. doi:10.1016/j.phrs.2014.01.004

Yang, X., An, N., Zhong, C., Guan, M., Jiang, Y., Li, X., et al. (2020). Enhanced Cardiomyocyte Reactive Oxygen Species Signaling Promotes Ibrutinib-Induced Atrial Fibrillation. Redox Biol. 30, 101432. doi:10.1016/j.redox.2020.101432

Yang, Y., Zhu, W.-Z., Joiner, M.-l., Zhang, R., Oddis, C. V., Hou, Y., et al. (2006). Calmodulin Kinase II Inhibition Protects against Myocardial Cell Apoptosis in vivo. Am. J. Physiology-Heart Circulatory Physiol. 291 (6), H3065-H3075. doi:10.1152/ajpheart.00353.2006

Yang, Z., Li, C., Wang, Y., Yang, J., Yin, Y., Liu, M., et al. (2018). Melatonin Attenuates Chronic Pain Related Myocardial Ischemic Susceptibility through Inhibiting RIP3-MLKL/CaMKII Dependent Necroptosis. J. Mol. Cell. Cardiol. 125, 185-194. doi:10.1016/j.yjmcc.2018.10.018

Yeung, H.-M., Hung, M.-W., Lau, C.-F., and Fung, M.-L. (2015). Cardioprotective Effects of Melatonin against Myocardial Injuries Induced by Chronic Intermittent Hypoxia in Rats. J. Pineal Res. 58 (1), 12-25. doi:10.1111/jpi.12190

Yoo, B., Lemaire, A., Mangmool, S., Wolf, M. J., Curcio, A., Mao, L., et al. (2009). $\beta 1$-Adrenergic Receptors Stimulate Cardiac Contractility and CaMKII Activation in vivo and Enhance Cardiac Dysfunction Following Myocardial Infarction. Am. J. Physiology-Heart Circulatory Physiol. 297 (4), H1377-H1386. doi:10.1152/ajpheart.00504.2009

Yoo, S., Aistrup, G., Shiferaw, Y., Ng, J., Mohler, P. J., Hund, T. J., et al. (2018). Oxidative Stress Creates a Unique, CaMKII-Mediated Substrate for Atrial Fibrillation in Heart Failure. JCI Insight 3 (21), e120728. doi:10.1172/jci.insight.120728

Yue, R.-C., Lu, S.-Z., Luo, Y., Wang, T., Liang, H., Zeng, J., et al. (2019). Calpain Silencing Alleviates Myocardial Ischemia-Reperfusion Injury through the NLRP3/ ASC/Caspase-1 axis in Mice. Life Sci. 233, 116631. doi:10.1016/j.lfs.2019.116631

Zareba, W., Daubert, J. P., Beck, C. A., Huang, D. T., Alexis, J. D., Brown, M. W., et al. (2018). Ranolazine in High-Risk Patients with Implanted CardioverterDefibrillators. J. Am. Coll. Cardiol. 72 (6), 636-645. doi:10.1016/j.jacc.2018.04.086

Zhang, M., Gao, H., Liu, D., Zhong, X., Shi, X., Yu, P., et al. (2019). CaMKII- $\delta 9$ Promotes Cardiomyopathy through Disrupting UBE2T-dependent DNA Repair. Nat. Cel Biol 21 (9), 1152-1163. doi:10.1038/s41556-019-0380-8

Zhang, M., Yang, X., Zimmerman, R. J., Wang, Q., Ross, M. A., Granger, J. M., et al. (2020). CaMKII Exacerbates Heart Failure Progression by Activating Class I HDACs. J. Mol. Cell Cardiol. 149, 73-81. doi:10.1016/j.yjmcc.2020.09.007

Zhang, T., Zhang, Y., Cui, M., Jin, L., Wang, Y., Lv, F., et al. (2016). CaMKII Is a RIP3 Substrate Mediating Ischemia- and Oxidative Stress-Induced Myocardial Necroptosis. Nat. Med. 22 (2), 175-182. doi:10.1038/nm.4017

Zhang, Y., Wang, W. E., Zhang, X., Li, Y., Chen, B., Liu, C., et al. (2019). Cardiomyocyte PKA Ablation Enhances Basal Contractility while Eliminates Cardiac $\beta$-Adrenergic Response without Adverse Effects on the Heart. Circ. Res. 124 (12), 1760-1777. doi:10.1161/circresaha.118.313417

Zhao, D., Liu, J., Wang, M., Zhang, X., and Zhou, M. (2019). Epidemiology of Cardiovascular Disease in China: Current Features and Implications. Nat. Rev. Cardiol. 16 (4), 203-212. doi:10.1038/s41569-018-0119-4

Zhong, P., Quan, D., Peng, J., Xiong, X., Liu, Y., Kong, B., et al. (2017). Role of CaMKII in Free Fatty Acid/hyperlipidemia-Induced Cardiac Remodeling both in vitro and in vivo. J. Mol. Cell. Cardiol. 109, 1. doi:10.1016/j.yjmcc.2017.06.010 
Zhou, H., Li, D., Zhu, P., Ma, Q., Toan, S., Wang, J., et al. (2018). Inhibitory Effect of Melatonin on Necroptosis via Repressing the Ripk3-PGAM5-CypD-mPTP Pathway Attenuates Cardiac Microvascular Ischemia-Reperfusion Injury. J. Pineal Res. 65 (3), e12503. doi:10.1111/jpi.12503

Zhou, M., Wang, H., Zhu, J., Chen, W., Wang, L., Liu, S., et al. (2016). Causespecific Mortality for 240 Causes in China during 1990-2013: a Systematic Subnational Analysis for the Global Burden of Disease Study 2013. The Lancet 387 (10015), 251-272. doi:10.1016/s0140-6736(15)00551-6

Zhu, H., Toan, S., Mui, D., and Zhou, H. (2021). Mitochondrial Quality Surveillance as a Therapeutic Target in Myocardial Infarction. Acta Physiol. (Oxf) 231 (3), e13590. doi:10.1111/apha.13590

Zou, L., Zhu-Mauldin, X., Marchase, R. B., Paterson, A. J., Liu, J., Yang, Q., et al. (2012). Glucose Deprivation-Induced Increase in Protein O-GlcNAcylation in Cardiomyocytes Is Calcium-dependent* . J. Biol. Chem. 287 (41), 34419-34431. doi:10.1074/jbc.m112.393207
Zybura, A. S., Baucum, A. J., Rush, A. M., Cummins, T. R., and Hudmon, A. (2020). CaMKII Enhances Voltage-Gated Sodium Channel Nav1.6 Activity and Neuronal Excitability. J. Biol. Chem. 295 (33), 11845-11865. doi:10.1074/jbc.ra120.014062

Conflict of Interest: The authors declare that the research was conducted in the absence of any commercial or financial relationships that could be construed as a potential conflict of interest.

Copyright (c) 2021 Yang, Jiang, Liu, Qin and Xiang. This is an open-access article distributed under the terms of the Creative Commons Attribution License (CC BY). The use, distribution or reproduction in other forums is permitted, provided the original author(s) and the copyright owner(s) are credited and that the original publication in this journal is cited, in accordance with accepted academic practice. No use, distribution or reproduction is permitted which does not comply with these terms. 


\section{GLOSSARY}

ADK Adenosine kinase

AngII Angiotensin II

AMPK Adenosine monophosphate-activated protein kinase

CaM Calmodulin

CaMKII $\mathrm{Ca}^{2+} / \mathrm{CaM}$-dependent protein kinase 11

CaMKIIa $\mathrm{Ca}^{2+} / \mathrm{CaM}$-dependent protein kinase 11 subtype $\alpha$

CaMKII $\beta \mathrm{Ca}^{2+} / \mathrm{CaM}$-dependent protein kinase ll subtype $\beta$

CaMKII $\gamma \mathrm{Ca}^{2+} / \mathrm{CaM}$-dependent protein kinase 11 subtype $\gamma$

CaMKII $\delta \mathrm{Ca}^{2+} / \mathrm{CaM}$-dependent protein kinase 11 subtype $\delta$

CaMKII $\delta 9 \mathrm{Ca}^{2+} / \mathrm{CaM}$-dependent protein kinase 11 subtype $\delta$ variant 9

CaMKIIISA $\mathrm{Ca}^{2+} / \mathrm{CaM}$-dependent protein kinase 11 subtype $\delta$ variant $\mathrm{A}$

CaMKIIISB $\mathrm{Ca}^{2+} / \mathrm{CaM}$-dependent protein kinase ll subtype $\delta$ variant $\mathrm{BCa}^{2+} / \mathrm{CaM}$-dependent protein kinase 11 subtype $\delta$ variant $\mathrm{C}$

CaMKIII $\delta \mathrm{B} \mathrm{Ca}^{2+} / \mathrm{CaM}$-dependent protein kinase ll subtype $\delta$ variant $\mathrm{BCa}^{2+} / \mathrm{CaM}$-dependent protein kinase 11 subtype $\delta$ variant $\mathrm{C}$

CAPN Calpain

ER Endoplasmic reticulum

HDAC Histone deacetylase

HF Heart failure

I/R Ischemia-reperfusion injury

ISO Isoproterenol

JNK2 c-Jun N-terminal kinase 2

KATP ATP-sensitive potassium channel

LTCC L-type calcium channel

MCP1 Monocyte chemotactic protein 1
MCU Mitochondrial calcium unidirectional transporter

MI Myocardial infarction

MLKL Mixed-lineage kinase domain-like protein mPTP Mitochondrial permeability transition pore

MsrA Methionine sulfone reductase A

NCX Sodium-calcium exchanger

NF- $\mathbf{k B}$ Nuclear factor $-\kappa \mathrm{B}$

NLRP3 Nod-like receptor protein 3

NLS Nuclear localization sequence

NO Nitric oxide

OGA O-GlcNAcase

O-GlcNAc O-linked N-acetylglucosamine

OGN O-GlcNAcylation protein

OGT O-GlcNAc transferase

PHD2 Proline hydroxylase 2

PLN Phospholamban

PKA Protein kinase A

RIP1 Receptor-interacting protein 1

RIP3 Receptor-interacting protein 3

ROS Reactive oxygen species

RyR2 Ryanodine receptor 2

SerCa2 Sarcoplasmic reticulum Ca (2+)-ATPase2

TNF- $\boldsymbol{\alpha}$ Tumor necrosis factor- $\alpha$

ULK1 UNC-51-like kinase 1

XIAP X-linked apoptotic protein inhibitor

$\boldsymbol{\beta} 1$-AR $\beta 1$-adrenergic receptor 